\title{
What is Fuzzy About Clustering in West Africa?
}

\author{
Charalambos Tsangarides and \\ Mahvash Saeed Qureshi
}





\title{
IMF Working Paper
}

\author{
African Department \\ What is Fuzzy About Clustering in West Africa? \\ Prepared by Charalambos Tsangarides and Mahvash Saeed Qureshi ${ }^{1}$
}

Authorized for distribution by Reza Vaez-Zadeh

March 2006

\begin{abstract}

\section{This Working Paper should not be reported as representing the views of the IMF.} The views expressed in this Working Paper are those of the author(s) and do not necessarily represent those of the IMF or IMF policy. Working Papers describe research in progress by the author(s) and are published to elicit comments and to further debate.
\end{abstract}

Applying techniques of clustering analysis to a set of variables suggested by the convergence criteria and the theory of optimal currency areas, this paper looks for country homogeneities to assess membership in the existing and proposed monetary unions of the broader west African region. Our analysis reveals considerable dissimilarities in the economic characteristics of the countries in west and central Africa. In particular, the West African Monetary Zone (WAMZ) countries do not form a cluster with the West Africa Economic and Monetary Union (WAEMU) countries; and, within the WAMZ, there is a significant lack of homogeneity. Furthermore, when west and central African countries are considered together, we find significant heterogeneities within the CFA franc zone, and some interesting similarities between the Economic and Monetary Community of Central Africa (CEMAC) and WAMZ countries. Overall, our findings raise some questions about the geographical boundaries of several existing and proposed monetary unions.

JEL Classification Numbers: F15, F33, C14, E61

Keywords: Monetary integration, west Africa, cluster analysis

Author(s) E-Mail Address: ctsangarides@imf.org; msq21@cam.ac.uk

\footnotetext{
${ }^{1}$ Mahvash Saeed Qureshi is currently a doctoral candidate at Trinity College, University of Cambridge, United Kingdom, and was an IMF summer intern at the time the research was conducted. We thank, without implicating, Anne-Marie Gulde-Wolf, Michael Hadjimichael, Cathy Pattillo, Ruby Randall, Ajit Singh, and Reza Vaez-Zadeh, for helpful comments and suggestions. All errors are our responsibility.
} 


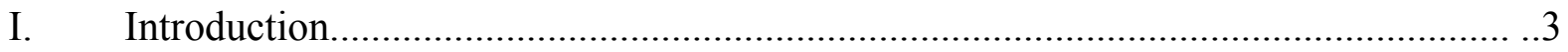

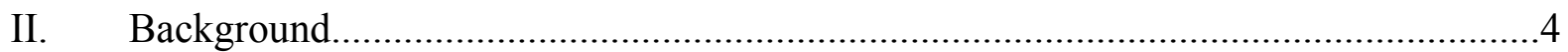

A. Optimum Currency Area and West Africa.............................................................

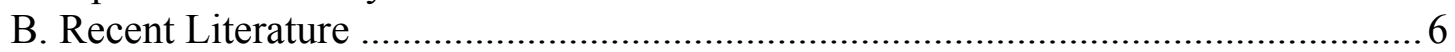

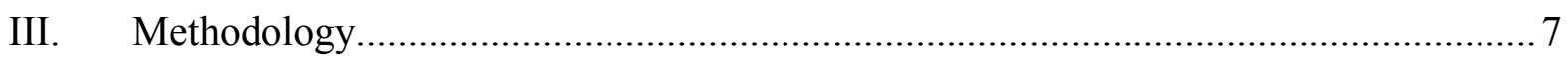

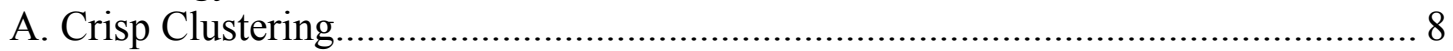

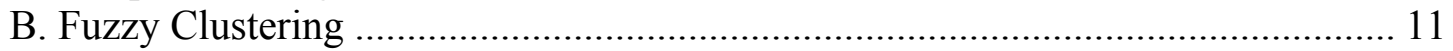

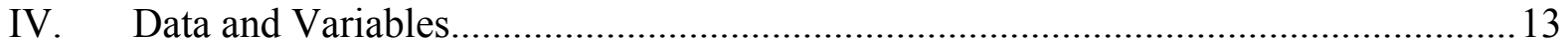

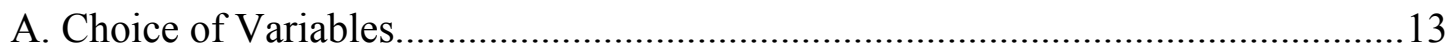

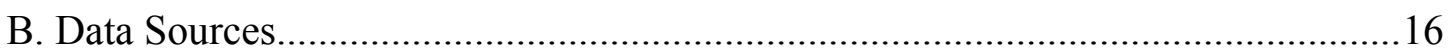

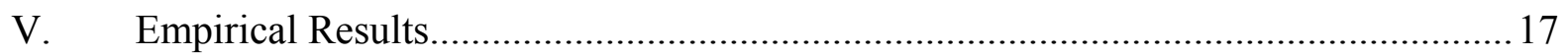

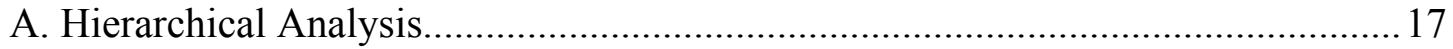

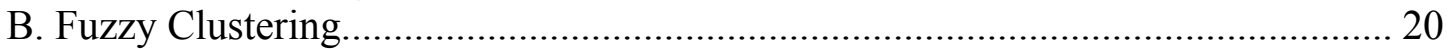

C. Empirical Evaluation: Principal Component Analysis..............................................24

D. Group Similarities: West Africa, Central Africa, and the Euro Area...................... 26

VI. Conclusion and Policy Implications............................................................................... 31

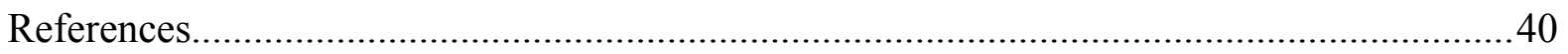

Appendices

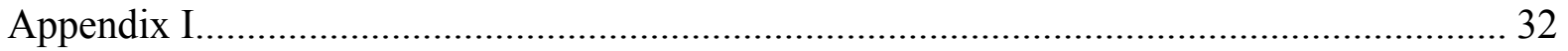

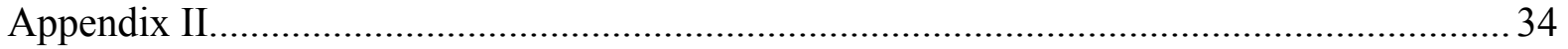

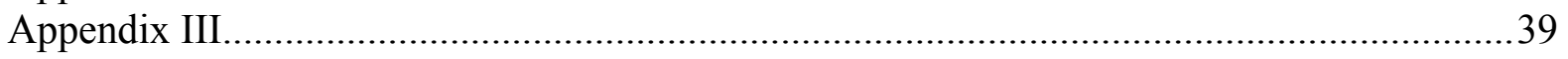

Tables

1. Membership coefficients for WAMZ countries..............................................................22

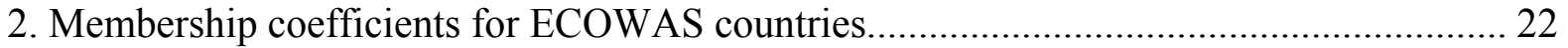

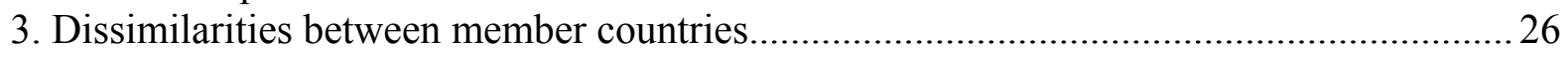

4. Membership coefficients for West and Central Africa....................................................... 30

5. Membership coefficients for the Euro Area....................................................................

Figures

1. Hierarchical Clustering Analysis: WAMZ Countries.......................................................19

2. Hierarchical Clustering Analysis: ECOWAS Countries....................................................19

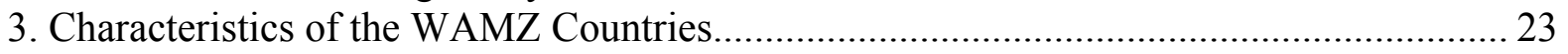

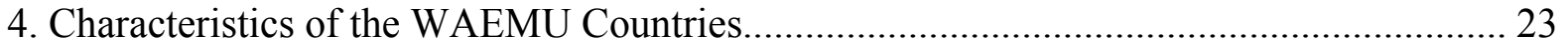

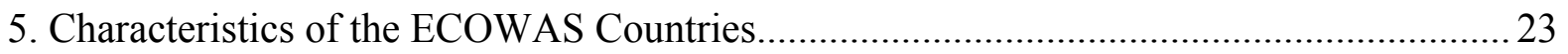

6. Clustering Based on Membership Coefficients................................................................ 24

7. Clustering Based on Principal Component Analysis …….................................................2

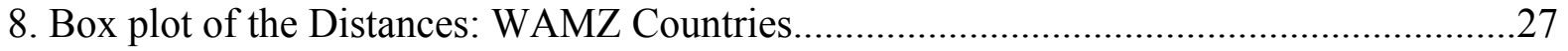

9. Box plot of the Distances: WAEMU Countries..................................................................2

10. Box plot of the Distances: ECOWAS Countries.............................................................. 27

11. Hierarchical Clustering Analysis: West and Central Africa..............................................2. 29

12. Hierarchical Clustering Analysis: the Euro Area.............................................................29 


\section{INTRODUCTION}

Following the successful launch of the euro as the single currency of the European Economic and Monetary Union (EMU), there has been a renewed interest internationally in the economics of monetary integration. Other regions are seeking to emulate the success of the EMU, usually by setting up similar institutional frameworks and establishing processes of convergence as prerequisites for wider monetary integration.

The objective of wider regional integration based on a reinforcement of regional surveillance and peer pressure for sound macroeconomic policy management is a welcome effort. In some cases, however, the drive for regional cooperation and integration has overshadowed concerns about the dissimilarities of the shocks accruing to the economies and of the economies' adjustment after they respond to the shocks - the key criteria of the optimum currency areas (OCA) theory as pioneered by Robert Mundell (1961). In this spirit, this paper tries to assess the comparative relevance of the proposed "monetary area boundaries" in West Africa and seeks to determine if the candidate countries are ready to form an OCA.

We use cluster analysis to provide an assessment of the readiness and sustainability of monetary unions by classifying West African countries into groups according to their performance towards achieving the OCA and convergence criteria for common currency adoption. Considering the noisy nature of the data, we employ the more realistic and powerful technique of fuzzy clustering along with the traditional hard clustering method. Fuzzy clustering techniques uncover useful relationships between countries in a group and the homogeneities among group members, by taking into account the possibility that a country may be similar to one country or group of countries in some respects and, at the same time, share certain other characteristics with another country or group of countries. In the end, a country is assigned the largest membership coefficient for the cluster with which it shares the greatest similarities.

The findings of our analysis reveal considerable dissimilarities in the economic characteristics of the countries in West Africa. In particular, the West African Monetary Zone (WAMZ) countries do not form a cluster with the West Africa Economic and Monetary Union (WAEMU) countries; and, within WAMZ, there is a significant lack of homogeneity, with Nigeria and Ghana appearing as independent singletons. These results cast doubt on the feasibility of a separate monetary union that comprises all WAMZ countries and more important, on the prospects of the wider monetary integration in the Economic Community of West African States (ECOWAS). Furthermore, when west and central African countries are considered together, we find significant heterogeneities within the CFA franc zone, with the WAEMU and Economic and Monetary Community of Central Africa (CEMAC) countries not clustering together, and some interesting similarities between the CEMAC and WAMZ countries, which tend to group together.

The rest of the paper is organized as follows. Section II presents a brief overview of the literature on currency unions in the context of the West African region. Section III describes in detail the methodology used in this paper. Section IV discusses the data and variables 
used in the empirical analysis. Section V presents the results and offers comparisons with other monetary unions. Section VI concludes and discusses the policy implications of our findings.

\section{BACKGROUND}

\section{A. Optimum Currency Areas and West Africa}

Several of the existing monetary arrangements in sub-Saharan Africa result from choices countries made during or after the colonial era: former British colonies moved from currency boards to flexible exchange rates after achieving independence, while after World War II, former French colonies and France set up a monetary arrangement in the form of the CFA franc (CFAF) zone. The CFAF zone comprises 14 countries grouped into two monetary unions, the WAEMU and CEMAC. ${ }^{2}$ A special case is the monetary union project in the ECOWAS. Founded in 1975, the ECOWAS is an organization of 15 members (8 of which are the members of the WAEMU), with the mandate to promote regional economic integration. Since April 2000, the five non-WAEMU members of ECOWAS (Nigeria, The Gambia, Ghana, Guinea, and Sierra Leone) have formed a second monetary area, the WAMZ, and established a convergence process toward launching a common currency. ${ }^{3}$ Wider monetary unification between member states of the ECOWAS is envisaged, although, to date, no announcement has been made of the type of monetary arrangement that would be adopted following the unification.

The standard tool used in economic literature to evaluate the adequacy of a currency union is the OCA theory, pioneered by Mundell (1961) and McKinnon (1963), with important elaborations by, among others, Kenen (1969) and Krugman (1990). The OCA theory compares the benefits and costs to countries of participating in a currency union. On the one hand, benefits include lower transaction costs, price stabilization, improved efficiency of resource allocation, and increased access to product, factor and financial markets (thereby facilitating investment and promoting economic growth). The main cost, on the other hand, is the country's loss of sovereignty to maintain national monetary and exchange rate policies.

Two criteria are identified in evaluating the feasibility of a monetary union - the nature of shocks affecting the potential monetary union member countries and the speed with which they adjust to them. First, when a country joins a common currency area, it relinquishes its own currency and abandons monetary policy and exchange rate autonomy. If all countries in

\footnotetext{
${ }^{2}$ Members of the WAEMU are Benin, Burkina Faso, Côte d'Ivoire, Guinea Bissau, Mali, Niger, Senegal and Togo. The CEMAC members are Cameroon, Chad, Republic of Congo, Central African Republic, Equatorial Guinea and Gabon. Equatorial Guinea and Guinea-Bissau, which are not former French colonies, joined the CFA zone in 1985 and 1997, respectively. Mali joined in 1984. See Hadjimichael and Galy (1997) for an analysis of the CFA zone and its institutions.

${ }^{3}$ The launch date of the common currency, initially set for July 2005, has been postponed to December 2009 because the WAMZ member states failed to achieve the convergence criteria.
} 
a currency area are hit with symmetric negative shocks, the adverse affects could be mitigated by depreciating the common currency or by adopting a common expansionary monetary policy. However, if countries are hit with asymmetric shocks, a depreciation or monetary expansion are not feasible instruments because they might boost production in countries with negative shocks but run the risk of triggering overheating and inflation in countries with positive shocks. Thus, the costs of forming a common currency area are lower if the shocks are symmetric, and higher if they are asymmetric.

Second, the speed with which economies adjust after shocks also has important implications for the formation of a currency union. If, after the shocks, market mechanisms are quick to restore equilibrium, then asymmetric shocks need not imply large costs even if they are large. Two such mechanisms that ensure rapid adjustment are labor mobility and fiscal transfers. For example, if labor can move freely throughout the currency area, unemployed workers in a country hit by an adverse shock could move to, and find jobs in, other parts of the currency area that experienced positive shocks, which would help mitigate the impact of a recession. Similarly, if the region has a good system of fiscal transfers, resources could be transferred from the country with positive shocks to countries affected by negative shocks. Adjustments in relative wages, changes in labor force participation induced by wage changes, and capital mobility are various other mechanisms for responding to shocks as discussed in Blanchard and Katz (1992).

The OCA criteria are a useful benchmark for evaluating the feasibility of monetary arrangements and may be used to analyze the establishment of the ECOWAS. First, the West African states are small, open economies that export primary commodities; they are not well diversified, and are highly susceptible to asymmetric shocks. Although some primary commodities, such as coffee, cocoa, cotton, fish, timber, and groundnuts are common to a number of countries, others are found in only one or two countries. Several countries depend on a single commodity for 50 percent or more of their earnings. ${ }^{4}$ In addition, terms of trade movements tend to be very large for most of these countries, with uncorrelated shocks to terms of trade mainly because of differences in commodity exports whose prices in world markets do not necessarily move together. For example, Nigeria, a large oil exporter, has terms of trade shocks that are very different from other WAMZ countries, which are all oil importers. Not only are the correlations with other members low (or negative), the variability in Nigeria's terms of trade changes is also large and higher than that of any other country in the region. ${ }^{5}$ In general, correlations of terms of trade shocks are higher among the WAEMU member countries than between WAEMU and WAMZ countries, or among the WAMZ countries themselves. ${ }^{6}$

\footnotetext{
${ }^{4}$ See Cashin and Pattillo (2000) and Masson and Pattillo (2005).

${ }^{5}$ See Masson and Pattillo (2001). Ogunkola (2002) studies bilateral real exchange rate volatility in the sub-Saharan African countries and finds the conditional volatility for Nigeria to be the highest in the region.

${ }^{6}$ See Table B3 in Appendix B.
} 
The asymmetry of shocks may be less of a problem if countries are sufficiently flexible, or if they have sufficient shock absorbers, in particular, factor mobility or a system of fiscal transfers. Although reliable migration data are hard to find, migration between the WAEMU and traditional migratory trade routes within West Africa seem high, albeit less high in recent years because of conflict. ${ }^{7}$ In contrast, fiscal transfers are inhibited by a lack of financial resources and the poor systems of transfers and taxes. In addition, trade within the ECOWAS region is relatively low. The WAEMU countries trade considerably more among themselves than with the non-WAEMU countries, whereas trade within the non-WAEMU countries is limited, which raises doubts about the magnitude of potential savings from a reduction in transactions costs. ${ }^{8}$

In principle, however, the West African countries stand to reap significant gains by giving up the pursuit of an independent monetary policy. Fixed exchange rates provide a way for countries to make a credible commitment to lower inflation and can help bring about price stability. ${ }^{9}$ In fact, in the absence of central bank independence and debt markets in which governments can finance themselves, monetary policy is generally dictated by the need to finance fiscal policy-persistent deficits lead to excessive money creation as governments resort to seigniorage. In this context, a monetary union could encourage fiscal discipline, and the common independent central bank could act as an "agent of restraint" for fiscal policies. ${ }^{10}$

\section{B. Recent Literature}

Much of the earlier research on monetary arrangements in Africa was carried out in the context of the CFA franc zone and examines whether economies in the CFA franc zone have fared better or worse than their neighbors that are not part of the zone. ${ }^{11}$ The asymmetry of shocks accruing to the sub-Saharan African (SSA) economies has been studied by Bayoumi and Ostry (1997), Hoffmaister, Roldos and Wickham (1998), and Fielding and Shields (2001) using the vector autoregressive (VAR) approach. They find little correlation of the disturbances to real output per capita among the SSA countries. Also, Hoffmaister, Roldos,

\footnotetext{
${ }^{7}$ See Masson and Pattillo (2001) and van den Boogaerde and Tsangarides (2005).

${ }^{8}$ This should be viewed in conjunction with the fact that the scope for intraregional trade is limited by low market potential, weak transportation infrastructure, and similarities in factor endowments. Further, benefits from reduced transaction costs do not seem to have translated into increased intraregional trade even in the CFA zone despite years of monetary unification. Trade within the CFA zone remains modest, especially within CEMAC, and practically nonexistent between WAEMU and CEMAC.

${ }^{9}$ However, Masson and Pattillo (2001) note that, so far, African countries with a common currency have not been successful in achieving price stability and have not made optimal monetary policy changes in response to various asymmetric shocks.

${ }^{10}$ In examining the CFA monetary union, Masson and Pattillo (2001) conclude, "a monetary union in West Africa can be an effective agency of restraint on fiscal policies if the hands of the fiscal authorities are also tied by a strong set of fiscal restraint criteria."

${ }^{11}$ See, for example, Devarajan and Rodrik (1991), Elbadawi and Majd (1996), and Ghura and Hadjimichael (1996).
} 
and Wickham (1998) show that external shocks are an important source of macroeconomic fluctuations in SSA and are more detrimental to CFA franc countries than to the non-CFA franc countries probably because of the fixed exchange rate regime in the former.

Recently, however, focus has shifted to analyzing the feasibility of forming a monetary union in the ECOWAS region perhaps because of the enthusiastic drive of the West African countries towards establishing a monetary union. Bénassy-Quéré and Coupet (2005) use cluster analysis to examine the monetary arrangements in the entire SSA region using the crisp clustering methodology only. Celasun and Justiniano (2005) use a dynamic factor analysis to study the synchronization of output fluctuations among the member countries. Their results indicate that small groups of countries within ECOWAS experience relatively more synchronized output fluctuations. They therefore suggest that monetary unification among subsets of countries is preferable to wider monetary integration in West Africa. Debrun, Masson and Pattillo (2005) develop a model of monetary and fiscal policy interactions and use it to assess the potential for monetary integration in ECOWAS. Their findings show that the proposed monetary union is desirable for most non-WAEMU countries but not for most of the existing WAEMU member states unless Nigeria implements institutional changes that lower its financing needs.

In general, it is difficult to assess the overall costs and benefits associated with a potential monetary union because of concerns about political commitment, credibility and endogeneity. The endogeneity concern of the OCA criteria, flagged by Frankel and Rose (1998), which implies that countries become similar when they share a common currency, is a particularly important issue but is not addressed in most cost-benefit analyses. Furthermore, despite a consensus about the dissimilarities in economic structures and asymmetries of shocks, the ECOWAS countries stand by their commitment to monetary integration for different socio-economic reasons. Against this background, in this paper we adopt a different approach and assess how well prepared and suitable West African states are to form a monetary union in light of their increased efforts toward macroeconomic convergence since 2000. In doing so, we investigate the homogeneity of the candidate countries in terms of a number of economic characteristics that are inspired from the OCA criteria as well as the convergence criteria set by these countries.

Our study differs from previous work in its approach as well in its methodology. We use clustering analysis to assess the similarity between countries within a region and across the regions. Cluster analysis offers a number of advantages. First, by allowing us to account for a number of variables simultaneously, it enables us to investigate synchronization in terms of the symmetry of business cycles as well as the symmetry of various other relevant variables. Second, cluster analysis has less stringent data requirements in terms of the time dimension of the data series than other methodologies and works well for countries for which consistent time-series data are limited, such as the African economies. Third, by exploring the group pattern in the data, this methodology identifies the areas in which each country needs to improve if it is to achieve macroeconomic convergence, which is necessary for forming the union, and provides useful information for making informed policy choices. 


\section{Methodology}

Cluster analysis refers to methods used to organize multivariate data into groups (clusters) according to homogeneities among the objects such that items in the same group are as similar as possible and items in different groups are as dissimilar as possible. ${ }^{12}$ The resulting data partition improves our understanding of the data by revealing its internal structure. Clustering is a useful exploratory tool that has been applied to a wide variety of research problems aiming to examine the underlying relationships in the data for classification, pattern recognition, model reduction, and optimization purposes. Broadly, clustering methodologies may be classified into two groups according to the types of clusters obtained: crisp (or hard) clustering approaches and soft (or fuzzy) clustering techniques.

\section{A. Crisp Clustering}

Crisp clustering algorithms divide the data into mutually exclusive clusters such that each object belongs to only one cluster. Mathematically, crisp partitioning of a dataset $\mathbf{X}$, with $N$ objects and $p$ variables, into $c$ clusters is defined as a family of subsets $\left\{A_{i} \mid 1 \leq i \leq c \subset X\right\}$ having the following properties:

$$
\begin{aligned}
& \bigcup_{i=1}^{c} A_{i}=X, \\
& A_{i} \cap A_{j}, 1 \leq i \neq j \leq c, \text { and } \\
& \Phi \subset A_{i} \subset X, 1 \leq i \leq c,
\end{aligned}
$$

where condition (1) states that the subsets $A_{\mathrm{i}}$ contain all data in $\mathbf{X}$; condition (2) states that the subsets must be disjoint so that each object belongs to one cluster only; and condition (3) states that none of the subsets is an empty set $(\Phi)$ or contains all the data in $\mathbf{X}$.

In terms of membership coefficients, $\mu_{i k}$, which indicate the degree of belongingness of an object $i$ to a cluster $k$, the above conditions may be expressed as

$$
\begin{aligned}
& \mu_{i k} \in 0,1 \text { and } 1 \leq i \leq N ; 1 \leq k \leq c, \\
& \sum_{k=1}^{c} \mu_{i k}=1,1 \leq i \leq N, \text { and } \\
& 0<\sum_{i=1}^{N} \mu_{i k}<N, 1 \leq k \leq c,
\end{aligned}
$$

\footnotetext{
${ }^{12}$ The term "similarity" however should be understood as mathematical similarity measured in a welldefined sense. In metric spaces, for example, similarity is defined by means of a distance function.
} 
where (4), (5) and (6) imply that a membership coefficient is either zero or one, the sum of the membership coefficients of an object across clusters is equal to one, and the sum of membership coefficients in a cluster lies between zero and the total number of objects in the dataset, respectively.

Different methods have been developed to partition data according to the above properties. These include hierarchical classification of data into groups and the classification of data based on the optimization of a numerical criterion. In this paper, we perform hard partitioning using the hierarchical clustering analysis-a procedure consisting of a series of partitions, which may run from a single cluster containing all individuals to $N$ clusters each containing a single individual. Hierarchical clustering can be performed using either the agglomerative methods, whereby successive fusions of individuals are made to a set containing all observations, or the divisive methods, whereby a set consisting of all individuals is divided successively into smaller groupings.

In this paper, we use the agglomerative method of hierarchical clustering and proceed by a series of successive fusions of the $N$ objects into groups until the last group consisting of all objects is reached. We begin by estimating the dissimilarities between every pair of objects using the Euclidean distance measure. ${ }^{13}$ Once the proximity between objects in the data set has been computed, the next step is to determine which objects should be grouped together into clusters. This is done by considering the distance information and linking pairs of objects that are close together into binary clusters (clusters made up of two objects). The newly formed clusters are then linked to other objects or clusters to create bigger clusters until all the objects in the original data set are linked together.

The linking of objects/clusters can be performed in various ways depending on how proximity between two groups of objects is measured. The commonly used methods of measurement or linkage functions include the Group Average, Ward, and Single linkage methods. The Group Average linkage method uses the average distance between all pairs of individuals in each group to calculate the distance between clusters. Thus, for two clusters (1 and 2) with $n_{1}$ and $n_{2}$ observations, respectively, this method measures proximity, dist, as

$$
\operatorname{dist}_{12}=\frac{1}{n_{1} n_{2}} \sum_{i=1}^{n} \sum_{j=1}^{n} d\left(x_{1 i}, x_{2 j}\right) \text {. }
$$

The Single linkage method, however, uses the nearest-neighbor distance or the smallest distance between objects in the two groups. In other words, it looks for an object in a cluster that is most closely placed to another object in a different cluster and uses the distance between the two objects as a measure of the closeness of clusters. That distance is expressed as

${ }^{13}$ The Euclidean distance between the row vectors $x_{1}$ and $x_{2}$ for an $n \times m$ matrix where $n$ is the number of objects and $m$ is the number of variables, is given by $d_{12}^{2}=\left(x_{1}-x_{2}\right)\left(x_{1}-x_{2}\right)^{\prime}$. For $n$ objects, this results in $n(n-1) / 2$ distance values. 


$$
\operatorname{dist}_{12}=\min \left\{d\left(x_{1 i}, x_{2 j}\right)\right\} ; i \in\left(1,2, \ldots, n_{1}\right), j \in\left(1,2, \ldots, n_{2}\right) .
$$

Finally, the Ward linkage uses the increase in the total within-cluster error sum of squares when two clusters are joined to determine the grouping of objects. It is defined as

$$
\operatorname{dist}_{12}=\frac{n_{1} n_{2} d^{2}\left(\bar{x}_{1}, \bar{x}_{2}\right)}{\left(n_{1}+n_{2}\right)},
$$

where $\bar{x}_{c}=\frac{1}{n_{1}} \sum_{i=1}^{n_{1}} x_{c i}$ is the center of each cluster and $d^{2}\left(\bar{x}_{1}, \bar{x}_{2}\right)$ is the distance between the centers of the two clusters.

The linking of objects in hierarchical clustering is presented in the form of a cluster tree known as a dendrogram. The tree is not a single set of clusters, but rather a multilevel hierarchy with clusters at one level being joined at the next higher level to form a bigger cluster, and so on. The heights of the 'links' of the dendrogram represent the distance at which each fusion is made such that the greater the dissimilarity between the objects or group of objects, the greater is the distance between them and the taller is the link.

We perform clustering using all the abovementioned linking approaches to investigate if the grouping of countries is affected by the choice of the proximity measure and to opt for the method that best represents our data. The results are then compared using the cophenetic correlation coefficient, which is a validity measure of the cluster information generated by the linkage functions. A cophenetic correlation coefficient measures the linear correlation between distances obtained from a cluster tree and the original distances (or dissimilarities) in the distance vector, which were used to construct the cluster tree. Therefore, it is a measure of how well the cluster tree represents dissimilarities among observations and reveals patterns present in the data set. Values of the cophenetic correlation coefficient close to one represent better clustering and indicate that the dendrogram does not greatly distort the original structure of the data input.

Determining the optimal number of clusters is a tricky task in hierarchical cluster analysis. In general, the appearance of the dendrogram itself is a natural guide to cluster divisions, where large changes in fusion levels are taken to indicate the best cut for forming clusters as suggested by Everitt, Landau and Leese (2001). ${ }^{14}$ A number of formal rules have also been proposed to determine the best number of clusters. However, earlier research indicates that because of deficiencies in each methodology, no single technique prevails for determining the appropriate number of clusters. Milligan and Cooper (1985) evaluate the performance of thirty cluster-stopping rules on four hierarchical methods and find that the pseudo-F index

\footnotetext{
${ }^{14}$ When the height of a link is consistent with the heights of its neighboring links, it is an indication of similarities between objects, whereas if the height of a link differs from its neighboring links, the link is said to be inconsistent and the object is considered different from the remaining elements.
} 
developed by Calinski and Harabasz (1974) is the best performer. This index, commonly known as the Calinski-Harabasz Index $(\mathrm{CHI})$, is a measure of the quality of the separation between clusters and is defined as

$$
C H I=\frac{S_{b} /(k-1)}{S_{w}(n-k)}
$$

where $S_{b}$ is the between clusters sum of squares, $S_{w}$ is the within clusters sum of squares, $k$ is the number of clusters, and $n$ is the number of observations. Higher values of the index indicate a distinct partitioning and better clustering. Hence, we use the $C H I$ to determine the best number of clusters as identified by the hierarchical analysis.

\section{B. Fuzzy Clustering}

The fuzzy cluster analysis draws on the fuzzy set theory attributed to Zadeh (1965). In conventional set theory, each element is attributed to one particular set such that if it is a member of one set then it cannot be a member of any other set. In fuzzy set theory, however, an element may be associated with more than one set, for each of which the degree of membership takes a value between zero and one. Similarly, in fuzzy clustering, objects are not forced to belong to one cluster or another, rather each object belongs to each cluster to some degree or the other. Objects in the data set are assigned membership coefficients between zero and one, which indicate their partial memberships or degree of belongingness to each cluster. ${ }^{15}$

Fuzzy clustering methodology is, therefore, different from crisp clustering primarily because it takes into account the realistic possibility that an object may share similarities with objects in other clusters and permits overlapping clusters. It therefore conveys more information about the data than crisp partitioning and is preferable to crisp partitioning. A number of algorithms have been proposed for fuzzy clustering: the fuzzy c-means algorithm (FCM), the Gustafson-Kessel algorithm (GK), the Gath-Geva algorithm (GG), and the fuzzy c-varieties algorithm (FCV). The FCM approach, however, remains the most prominent algorithm and is used in this paper for grouping purposes. The FCM, developed by Dunn (1974) and further developed by Bezdek (1981), is based on the minimization of an objective function called the c-means functional, which has been defined by Dunn (1974) as follows:

$$
J(\mu, v)=\sum_{i=1}^{N} \sum_{k=1}^{c}\left(\mu_{i k}\right)^{2} d^{2}\left(x_{i}, v_{k}\right)=\sum_{i=1}^{N} \sum_{k=1}^{c} \mu_{i k}^{2} \sum_{j=1}^{m}\left(x_{i j}-v_{k j}\right)^{2},
$$

\footnotetext{
${ }^{15}$ A membership coefficient close to or equal to zero suggests that the object is dissimilar to other objects in that cluster whereas a membership coefficient closer to or equal to one indicates that the object is highly similar to other objects in that cluster.
} 
where $d$ is the Euclidean distance between an object $x_{\mathrm{i}}$ and the centre of the cluster $k, \mu_{\mathrm{ik}}$ is the degree of membership that $x_{i}$ belongs to the centre of each cluster $v_{k}$, and $v_{k}$ is calculated for each variable $j$ as follows: ${ }^{16}$

$$
v_{k j}=\sum_{i=1}^{N} u_{i k}^{2} x_{i j} / \sum_{i=1}^{N} u_{i k}^{2} .
$$

The minimization of (11) is subject to the following constraints:

$$
\begin{aligned}
& 0 \leq \mu_{i k} \leq 1, \\
& \sum_{k=1}^{c} \mu_{i k}=1, \quad 1 \leq i \leq N, \text { and } \\
& 0<\sum_{i=1}^{N} \mu_{i k}<N, 1 \leq k \leq c .
\end{aligned}
$$

where the first constraint implies that the membership coefficients may take any value in the closed interval zero and one subject to constraints that are similar to the constraints (5) and (6), respectively. This is in contrast to the hard partitioning conditions, which force the membership coefficients to take values of zero or one only.

Like other optimization clustering methods, the fuzzy clustering methodology finds the best fit for a fixed number of clusters but does not ensure that it is the best possible fit for the data overall. To ensure that the chosen number of clusters gives an optimal representation of data, the clustering results needs to be validated. In particular, cluster validation is the task of determining the quality of cluster structures and assessing whether they reflect the data accurately (Zimmermann, 1991). A number of validation measures have been proposed in the literature to assess the goodness of the obtained partitions. They include the indices by Dunn (1976), Rouben (1982), Rousseeuw (1987), and Xie and Beni (1991). As none of the indices is reliable by itself, Balasko, Abonyi and Feil (2004) suggest that the optimal number of clusters should be chosen after comparing results from several indices. In this paper, we use three frequently applied measures - the Dunn's Partition Coefficient (DPC), Xie and Beni's Index (XBI), and the silhouette plot - to determine the number of optimal clusters and to assess the effectiveness of our analysis. These three validity measures are discussed in Appendix I.

${ }^{16}$ The Euclidean distance $d$ is defined as $d\left(x_{i}, v_{k}\right)=\left[\sum_{j=1}^{m}\left(x_{k j}-v_{i j}\right)^{2}\right]^{1 / 2}$. 


\section{DATA ANd VARIABLes}

\section{A. Choice of Variables}

The choice of variables in clustering depends on the purpose of partitioning and the availability of data. In this paper, we explore the feasibility of the proposed currency union in West Africa by examining whether the economic structures of the candidates are similar enough to support a fixed exchange rate arrangement between their currencies. Therefore, our choice of variables is based on the OCA literature as well as on the convergence criteria set for establishing a monetary zone in the region. ${ }^{17}$ In particular, we use variables that measure the synchronization of output and terms of trade shocks, exchange rate variability, inflation, regional trade intensity of individual countries, and government balance. We also include the debt-servicing requirement as a variable because the West African states spend a large part of their foreign exchange earnings to service their debts. ${ }^{18}$ Finally, to attach equal weights to all variables, we perform clustering on normalized variables, where we achieve normalization by taking the deviation of each variable from its mean and dividing by its respective standard deviation. The construction of each variable is described in detail below. $^{19}$

\section{Output volatility}

Measuring the synchronization of business cycles between countries requires the choice of an anchor country (or a group of countries) for computing correlations. For example, before EMU, Germany was considered as the internal anchor country, and the European Central Bank was modeled after the Bundesbank. Therefore, research on the European Union (EU) has focused on Germany as the central country and assessed the performance of individual countries with respect to Germany (Artis and Zhang 2001, 2002; Boreiko, 2003; and Kozluk 2003). However, for Africa, the choice of an anchor country for assessing the feasibility of monetary arrangements is unclear. Nigeria, one candidate for West Africa, lacks the financial development and disciplined fiscal policies of Germany and has an export structure that differs greatly from its neighbors. Hence, it has the potential to influence monetary policies in ways that partners in a monetary union would find undesirable and is therefore not suitable as an anchor country. An alternative strategy therefore is to use an area outside of West Africa as a benchmark. Therefore, following Bénassy-Quéré and Coupet (2005), we calculate

\footnotetext{
${ }^{17}$ Clustering was performed considering the OCA and convergence criteria separately as well as taking all the variables together. However, since this did not have any significant effect on the groupings, we report the results for the latter only for brevity reasons. All results are available from the authors upon request.

${ }^{18}$ In general, countries with higher debt-service ratios are expected to be more willing to peg and less inclined to devalue, as debt servicing is denominated in hard currencies (Bénassy-Quéré and Coupet, 2005).

${ }^{19}$ See Appendix B for time series plots of the variables.
} 
the correlation of business cycles of the West African countries with respect to the euro area. $^{20}$

In the first step of estimating the synchronization of output shocks between ECOWAS countries, the Hodrick-Prescott filter is used to detrend the annual real GDP series of all ECOWAS countries as well as the aggregate real GDP series of the euro area. Next, crosscorrelations of the cyclical components of the individual GDP series are estimated vis-à-vis the euro area. ${ }^{21}$ West African countries with similar correlation values, whether positive or negative, are considered to have relatively parallel business cycles. However, when the correlation coefficients are different in magnitude or in sign, they indicate no correlation of output shocks and higher costs of joining the monetary union. During 1995-2004, the average correlation of output fluctuations was higher for the WAEMU region as compared to the average correlation for the WAMZ region as well as for the entire ECOWAS region. ${ }^{22}$

\section{Terms of trade synchronization}

Large swings in terms of trade are an important source of shocks, especially for countries that rely heavily on the exports of primary commodities for their foreign exchange earnings. The costs of monetary unification are higher if terms of trade shocks are not well correlated across countries, because the exchange rate is no longer available as an instrument to cushion against these shocks. To measure the cross-correlation of terms of trade movements, we again assign the anchor role to the Euro Area. To compute changes in the terms of trade for every country, we take the first difference of the annual terms of trade index and measure correlation with the annual change in the aggregate terms of trade index series for the euro area. As before, countries with similar values of the correlation coefficient, positive or negative, are considered to have relatively parallel terms of trade shocks, whereas dissimilar coefficients represent asymmetric shocks. Overall, WAEMU countries appear to have more synchronized terms of trade changes than the WAMZ countries. ${ }^{23}$

\section{Real exchange rate variability}

The OCA theory emphasizes that the primary costs to countries of monetary unification stem from the loss of maintaining a flexible exchange rate, which, under monetary independence, they can use as a policy tool to absorb any supply and demand shocks hitting the economy. Hence, for countries with a small variation in exchange rates, abandoning monetary policy

\footnotetext{
${ }^{20}$ Bénassy-Quére and Coupet (2005) point out that the euro area is preferable to any other country or region as an anchor because of the current CFA arrangement, as well as because of the large trade flows between the two regions.

${ }^{21}$ Correlations are also estimated using annual GDP growth rates. This did not alter the results in any way.

${ }^{22}$ See Table B1 in Appendix B for cross-correlation in output fluctuations of the ECOWAS countries.

${ }^{23}$ See Table B2 in Appendix B for cross-correlation in terms of trade changes of the ECOWAS countries.
} 
independence might cause little concern, and vice versa. We measure the variability in exchange rates as the standard deviation of the log difference of annual real exchange rates of individual countries. However, we include this variable while examining the grouping of the WAMZ countries only. The ECOWAS arrangement includes both non-CFA (WAMZ) countries and CFA (WAEMU) countries; the latter already have a pegged exchange rate system in place. Thus, using the volatility of the exchange rate as a criterion for examining similarities is not appropriate for all ECOWAS member countries.

\section{Regional trade intensity}

Regional trade intensity is measured as a ratio of the sum of exports and imports between a country and the rest of the region to the sum of that country's total exports and imports. Thus, for any country $i$ in the sample, trade intensity with the WAMZ and ECOWAS groups is given by $\left(X_{i, W A M Z}+M_{i, W A M Z}\right) /\left(X_{i}+M_{i}\right)$ and $\left(X_{i, E C O W A S}+M_{i, E C O W A S}\right) /\left(X_{i}+M_{i}\right)$, respectively, where $X$ represents exports and $M$ denotes imports. We compute the annual regional trade intensity for each country and average it over the sample period. A higher value of trade intensity indicates greater intraregional trade and larger gains from joining the currency union. Statistics reveal that the average regional trade intensity among the WAMZ countries and between the WAMZ and WAEMU countries remains low; however, it is considerably higher among the WAMEU countries. ${ }^{24}$

\section{Inflation}

The primary criteria set by WAMZ for achieving macroeconomic convergence to establish the desired monetary union includes maintaining the inflation rate at a single-digit level. ${ }^{25}$ We construct the inflation rate variable for each country by taking the log difference of the annual consumer price index and averaging across the years. Overall, the average annual percentage change in prices was higher for WAMZ countries than for the WAEMU countries during 1995-2004. ${ }^{26}$

\section{Government balance}

Another primary convergence criterion for establishing WAMZ is a budget deficit to GDP ratio (excluding grants) of less than 4 percent. This ratio is calculated by taking the annual central government balance (excluding grants) as a percentage of annual GDP and then averaging observations for every country. The WAMZ countries have generally been running

\footnotetext{
${ }^{24}$ See Figure B1 in Appendix B.

${ }^{25}$ The WAEMU primary convergence criterion limits inflation to below 3 percent.

${ }^{26}$ Among the WAMZ countries, for which the inflation target is single-digit annual rates, the average rate for The Gambia and Guinea remained in single digits; however, Ghana, Nigeria, and Sierra Leone recorded double-digit average inflation rates. In the WAEMU group, with the notable exception of Guinea-Bissau (14.5 percent), the average inflation rate for member countries remained between 2.0 and 4.0 percent.
} 
fiscal deficits and have found it difficult to meet the benchmark as prescribed in the convergence criteria (see Appendix II).

\section{Debt-servicing requirement}

Debt servicing is a major problem for the West African states, which allocate a significant proportion of the export revenue to meet their debt-servicing obligations. The convergence criteria require member countries to build up surpluses to attain sustainable debt levels so as to ensure that they service their debt stock without inflating their economy by increasing the money supply or borrowing further to repay existing debt. We represent debt servicing for every country as the average of the ratio of its debt-servicing requirements to its total exports of goods and services. Although for the WAMZ countries the ratio has been steadily declining over the years, the average ratio in recent years still exceeds the threshold of debt sustainability of 10 percent (see Appendix II).

\section{B. Data Sources}

Data for the above variables have been compiled on an annual basis from various sources. The real and nominal GDP series, terms of trade index, consumer price index, and government balance statistics are obtained from the IMF's World Economic Outlook, April 2005. The regional trade intensity variable has been computed using bilateral data from the IMF's Direction of Trade Statistics. The debt-servicing ratio has been compiled from the World Bank's World Development Indicators 2004 and the African Development Indicators 2004 databases. Information on the effective real exchange rate is taken from the Information Notice Systems (INS) database, which provides monthly exchange rate statistics. The monthly exchange rate values are averaged to estimate the average annual exchange rate for every country.

Clustering is applied to two different samples of countries. The first sample consists of the non-WAEMU countries except Liberia, for which complete data series are unavailable. Since five out of the six non-WAEMU countries belong to the WAMZ group, we refer to the nonWAEMU countries as the WAMZ group henceforth. ${ }^{27}$ Clustering of WAMZ countries allows us to examine the performance of countries in the WAMZ region in terms of the OCA and the established primary macroeconomic convergence criteria. The second samplecomprising of the ECOWAS member countries, that is, the WAMZ and WAEMU countries taken together-allows us to assess the similarities and dissimilarities among the economic characteristics of countries to be included in the proposed larger West African monetary union.

\footnotetext{
${ }^{27}$ Cape Verde has yet to formalize its membership of the WAMZ group. It was not a signatory of the "Accra declaration" on the creation of WAMZ.
} 


\section{EMPIRICAL RESULTS}

Clustering of the West African states is performed for three overlapping periods (1990-2004, 1995-2004, and 2000-04), making it possible to analyze the extent to which the changing national and international policy environments have influenced homogeneity across countries over time. ${ }^{28}$ The results for both hierarchical and fuzzy clustering reveal a high degree of similarity between groupings for the time periods 1990-2004 and 1995-2004. Therefore, we present and discuss our findings for 1995-2004 and 2000-04 only. For policy purposes, the results obtained for 2000-04 may be more relevant because they indicate the progress countries made toward monetary unification after the inception of the WAMZ.

\section{A. Hierarchical Analysis}

Figures 1 and 2 present the hierarchical clustering of the WAMZ and ECOWAS countries, respectively. In each figure, the horizontal axis represents countries included in the sample, and the vertical axis indicates distances (or dissimilarities) between the countries. The cophenetic coefficient (reported with the dendrogram in each case) has a reasonably high value in all cases and indicates that the cluster information generated by the dendrogram is a good representation of dissimilarities in the original data. In addition, the results obtained from the hierarchical clustering of the WAMZ and ECOWAS countries show that the groupings do not depend on the type of agglomerative method used and remain similar across the Group Average, Ward, and Single linkage aggregation algorithms. Since the cophenetic correlation coefficient corresponding to the Group Average linkage function is the highest for all samples, we discuss its results in this section. ${ }^{29}$

For the WAMZ countries, the Calinski-Harabasz Index $(C H I)$ attains the highest value when the number of clusters is equal to four (see Appendix III). Based on this, The Gambia, Guinea, and Cape Verde form one group, whereas Ghana, Nigeria, and Sierra Leone are singletons. This finding is supported by an inspection of the two panels of Figure 1, which illustrate that, among the WAMZ countries, The Gambia, Guinea, and Cape Verde are linked to each other at relatively smaller distances in both time periods and that the remaining three countries join the group at much higher distances (indicating larger dissimilarities).

In Figure 2, both the WAEMU and WAMZ countries are considered together. For the period 1995-2004, the $C H I$ suggests that six is the optimal number of clusters. ${ }^{30}$ The first group consists of five WAEMU countries - Benin, Burkina Faso, Mali, Niger, and Togo. The second group comprises two WAEMU countries (Côte d'Ivoire and Senegal) and two

\footnotetext{
${ }^{28}$ Grouping countries based on the latest data point only is not recommended because a country's performance in one year might not reflect its policy management.

${ }^{29}$ Results for the Ward and Single linkage algorithms are presented in Appendix B.

${ }^{30}$ In general, it has been suggested that an effective representation of data requires that the number of clusters be neither too small nor too large. As our sample contains 14 elements, considering a solution with more than 7 groups does not seem feasible. We therefore examine the $\mathrm{CHI}$ for 2-6 cluster solutions only.
} 
WAMZ countries (The Gambia and Guinea). The third group consists of Ghana and Sierra Leone. The remaining three groups contain Cape Verde, Nigeria, and Guinea-Bissau as singletons. For 2000-04, the composition of clusters (as suggested by the CHI values) suggests a grouping the data into five clusters that is not too different from the 1995-2004 grouping. The first group now includes Senegal in addition to Benin, Burkina Faso, Mali, Niger, and Togo. Cape Verde, Côte d'Ivoire, The Gambia, and Guinea form the second group. Guinea-Bissau and Sierra Leone make up the third group. Once again, Ghana and Nigeria do not seem to be part of any group.

In summary, based on hierarchical analysis, we notice that all the WAEMU countries except Guinea-Bissau group together and link with each other at relatively smaller distances. The WAMZ countries link with each other as well as with the WAEMU countries at higher link lengths. Overall, Ghana, Guinea-Bissau, Nigeria, and Sierra Leone appear to be the most different in terms of the macroeconomic attributes considered here. 


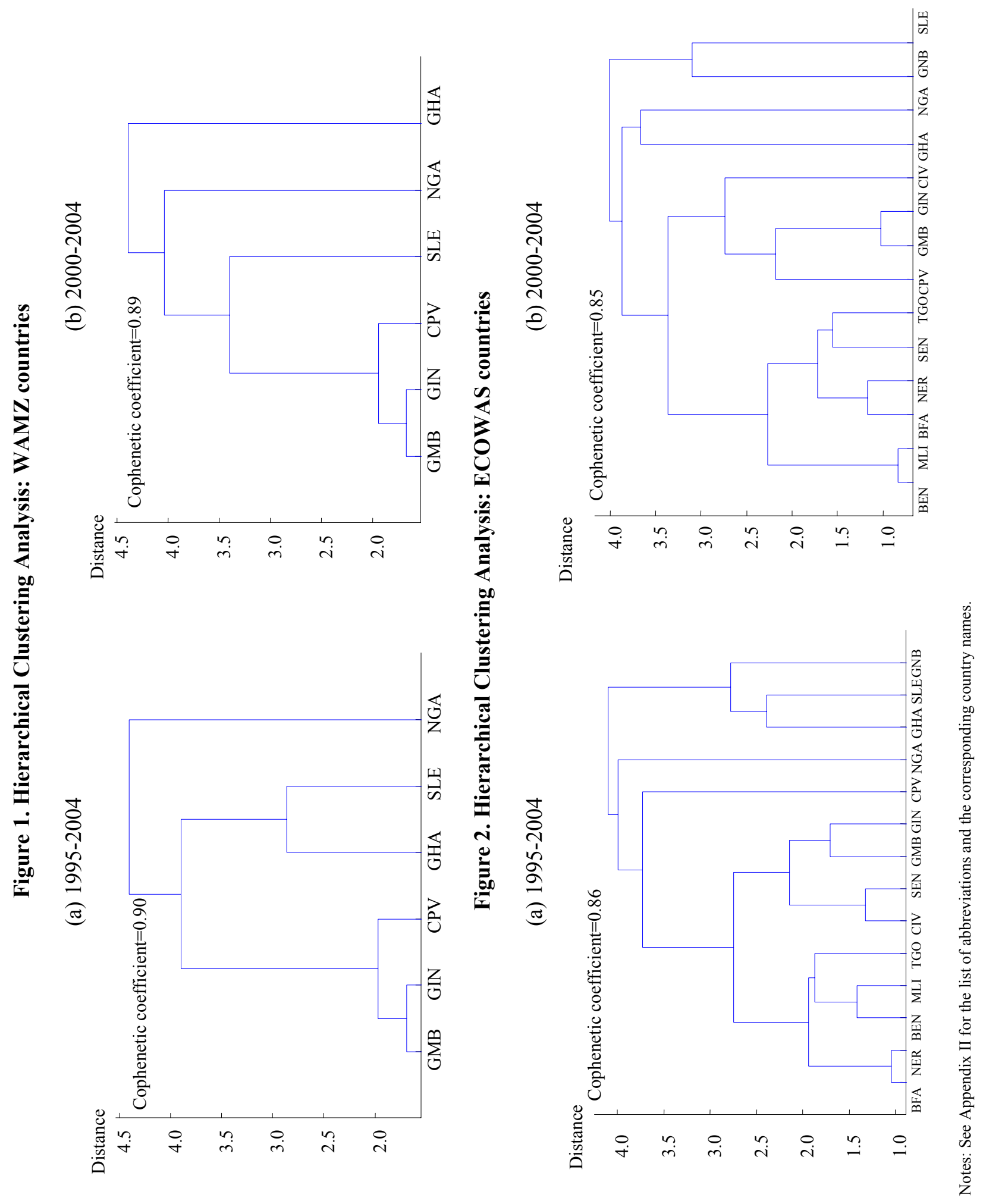




\section{B. Fuzzy Clustering}

The results obtained from the fuzzy clustering of the WAMZ countries are reported in Table 1. The validity statistics-namely, the Dunn's partition coefficient $(D P C)$, the silhouette width $(S W)$, and the Xie and Beni's index $(X B I)$-indicate the presence of three clusters for 19952004 and of four clusters for 2000-04. Cape Verde, The Gambia, and Guinea have the highest membership coefficients for the same cluster during both time periods. Nigeria forms its own cluster, whereas Ghana and Sierra Leone have the highest membership coefficients for the same cluster if the longer data series is considered but not during the most recent time period.

We observe less fuzziness in the partitioning of clusters during 2000-04 than during 19952004. Countries that form a group in both years-that is, Cape Verde, The Gambia, and Guinea-experience positive but not very high correlation of business cycles and terms of trade changes with each other, relatively lower real exchange rate volatility, low trade intensity within the WAMZ region, low average inflation, and low debt-service requirements. However, their statistics for average government balance to GDP ratio and real exchange rate volatility are less uniform (Figure 3).

Ghana and Sierra Leone have the highest membership coefficient for the same cluster in 1995-2004 and have positive and relatively high correlation coefficients for output variation and terms of trade changes. However, as is evident from the low average silhouette width of their cluster, they are not very similar in terms of other characteristics. The most outstanding characteristic of Sierra Leone is its large debt-servicing requirements. Ghana is the country with the highest within-region trade intensity. It experienced relatively moderate exchange rate volatility and high average inflation during 1995-2004 but greater real exchange rate fluctuations during 2000-04.

Nigeria has idiosyncratic characteristics and is therefore an outlier in both sets of results. It has weak correlation of business cycles and negative correlation of terms of trade changes with other countries, moderate average inflation, a low budget deficit to GDP ratio, and low regional trade intensity. However, a notable reduction is evident in its real exchange rate volatility during the recent period.

Broadly speaking, the results from fuzzy clustering appear to be consistent with the grouping suggested by crisp clustering in Figure 1. Based on these results, we may conclude that considerable dissimilarities remain in the economic characteristics of the WAMZ countries. Countries differ in not only the output and terms of trade shocks they experience, but also in terms of the progress they have made toward meeting the primary convergence criteria, which are a prerequisite for establishing a monetary union in the region.

Table 2 presents the membership coefficients and the validity statistics for the ECOWAS countries. In performing fuzzy clustering, we evaluate two to six clusters because of the small number of observations in our data set. The validity statistics of the estimations indicate the presence of five clusters in our data for both time periods. The DPC and 
silhouette width are very small (less than 0.500 ) in both cases and reveal a substantial lack of structure, that is, fuzziness in the data. However, the statistics for the most recent time period are slightly better and indicate improved within-cluster similarity and better cluster partitioning.

For 1995-2004, the best performing cluster comprises four WAEMU countries: Burkina Faso, Mali, Niger, and Togo. These four countries have a silhouette width greater than 0.500 and an average silhouette width of 0.614 . They have well-correlated business cycle movements, relatively greater regional trade intensity, low inflation rates, and low budget deficits. The other cluster with an average silhouette width of greater than 0.500 comprises Ghana, Guinea-Bissau, and Sierra Leone. These countries have higher government deficit to GDP ratios and relatively higher inflation rates and debt servicing requirements. The output fluctuations of Ghana and Sierra Leone are relatively synchronized, but the same does not hold for Guinea-Bissau. The three countries, however, experience dissimilar terms of trade shocks.

Côte d'Ivoire, Guinea, and Senegal have the highest membership coefficients for the same cluster. The comparative statistics in Figure 3 show that the three countries had low average inflation, higher budget deficits ratio, and positive but low business cycle correlations although they differ in terms of other statistics. Guinea, however, has a lower membership coefficient (less than 0.500) than the other two countries and a negative silhouette width if forced to be included in this cluster. This is probably because of its high membership coefficient for the first cluster, which indicates that it also shared similarities with Cape Verde and The Gambia.

Cape Verde and The Gambia form another cluster based on the membership coefficients although as shown in Table 2, The Gambia does not have a very low membership coefficient for cluster IV either, which indicates some similarity of characteristics with countries in that group. Surprisingly, Benin and Nigeria have the highest membership coefficients for the same group, although the silhouette width for Benin indicates that it does not belong to the same cluster as Nigeria. Nigeria experienced output and terms of trade shocks that are very different from those experienced by other countries in the region; it therefore seems best to identify Nigeria as a separate group.

Analysis of the period 2000-04 does not reveal much difference in countries' economic performance. The clustering algorithm identifies five groups of countries in the data where most of the WAEMU countries cluster together. Benin and Mali, which experience symmetrical terms of trade and output shocks form one group. Guinea-Bissau and Sierra Leone continue to be in the same group, and Nigeria is identified as a singleton. Cape Verde, Côte d'Ivoire, The Gambia, Ghana, and Guinea have the highest membership coefficients for the same cluster, but the silhouette widths and the magnitudes of their membership coefficients indicate that only Cape Verde, The Gambia, and Guinea are well specified in the cluster. Strict classification of Cote d'Ivoire and Ghana is not clear. Côte d'Ivoire differs from other countries mainly in terms of its output fluctuations, whereas Ghana has a high average inflation rate. 
Figure 6 summarizes the findings of fuzzy clustering if groupings are forced on the basis of the highest membership coefficients across rows. It is reassuring to see that, overall, results from fuzzy clustering are very similar to the groupings obtained from hierarchical clustering. With the notable exception of Guinea-Bissau, the remaining WAEMU countries are grouped together. Of the WAMZ countries, Cape Verde, The Gambia, and Guinea and are relatively similar to each other but different from the rest of the ECOWAS group. Ghana does not have much in common, and therefore cannot be identified, with one particular group or country. The same is true for Nigeria, whose behavior pertaining to terms of trade shocks, inflation and exchange rate variability is highly idiosyncratic.

Table 1. Membership Coefficients for WAMZ Countries

\begin{tabular}{|c|c|c|c|c|c|c|c|c|c|}
\hline & \multirow[b]{2}{*}{ I } & \multicolumn{2}{|c|}{$1995-2004$} & \multirow[b]{2}{*}{ SW } & \multirow[b]{2}{*}{ I } & \multicolumn{3}{|c|}{$2000-04$} & \multirow[b]{2}{*}{ SW } \\
\hline & & II & III & & & II & III & IV & \\
\hline Cape Verde & 0.883 & 0.068 & 0.049 & 0.805 & 0.844 & 0.069 & 0.037 & 0.050 & 0.750 \\
\hline Gambia, The & 0.909 & 0.057 & 0.034 & 0.758 & 0.719 & 0.125 & 0.080 & 0.077 & 0.594 \\
\hline Ghana & 0.064 & 0.869 & 0.067 & 0.524 & 0.000 & 0.000 & 1.000 & 0.000 & 1.000 \\
\hline Guinea & 0.824 & 0.094 & 0.082 & 0.736 & 0.827 & 0.065 & 0.039 & 0.069 & 0.713 \\
\hline Nigeria & 0.001 & 0.001 & 0.999 & 1.000 & 0.000 & 0.000 & 0.000 & 1.000 & 1.000 \\
\hline Sierra Leone & 0.197 & 0.691 & 0.112 & 0.325 & 0.001 & 0.999 & 0.000 & 0.000 & 1.000 \\
\hline Avg. SW & 0.766 & 0.425 & 1.000 & 0.691 & 0.686 & 1.000 & 1.000 & 1.000 & 0.843 \\
\hline DPC (normalized) & 0.650 & & & & 0.768 & & & & \\
\hline $\mathrm{DPC}$ & 0.767 & & & & 0.826 & & & & \\
\hline XBI & 1.135 & & & & 1.378 & & & & \\
\hline
\end{tabular}

Notes: SW, DPC and XBI denote the silhouette width, Dunn's Partition Coefficient and Xie and Beni's Index, respectively. Avg. SW represents the average silhouette width of clusters if objects are forced to belong to each cluster according to their membership coefficients.

Table 2. Membership Coefficients for ECOWAS Countries

\begin{tabular}{|c|c|c|c|c|c|c|c|c|c|c|c|c|}
\hline & \multirow[b]{2}{*}{ I } & \multicolumn{4}{|c|}{$1995-2004$} & \multirow[b]{2}{*}{ SW } & \multirow[b]{2}{*}{ I } & \multicolumn{4}{|c|}{$2000-04$} & \multirow[b]{2}{*}{ SW } \\
\hline & & II & III & IV & $\mathrm{V}$ & & & II & III & IV & $\mathrm{V}$ & \\
\hline Benin & 0.029 & 0.813 & 0.017 & 0.061 & 0.080 & -0.468 & 0.030 & 0.050 & 0.839 & 0.065 & 0.016 & 0.880 \\
\hline Burkina Faso & 0.008 & 0.031 & 0.008 & 0.030 & 0.923 & 0.731 & 0.036 & 0.021 & 0.101 & 0.819 & 0.023 & 0.512 \\
\hline Cape Verde & 0.942 & 0.017 & 0.012 & 0.018 & 0.012 & 0.613 & 0.502 & 0.093 & 0.144 & 0.138 & 0.123 & 0.269 \\
\hline Côte d'Ivoire & 0.039 & 0.068 & 0.055 & 0.732 & 0.107 & 0.436 & 0.380 & 0.100 & 0.148 & 0.234 & 0.139 & -0.091 \\
\hline Gambia, The & 0.373 & 0.118 & 0.098 & 0.298 & 0.113 & -0.066 & 0.878 & 0.022 & 0.032 & 0.040 & 0.029 & 0.395 \\
\hline Ghana & 0.070 & 0.090 & 0.635 & 0.111 & 0.095 & 0.498 & 0.261 & 0.204 & 0.145 & 0.172 & 0.219 & -0.071 \\
\hline Guinea & 0.256 & 0.233 & 0.087 & 0.314 & 0.109 & -0.065 & 0.882 & 0.029 & 0.030 & 0.031 & 0.029 & 0.535 \\
\hline Guinea-Bissau & 0.108 & 0.132 & 0.520 & 0.118 & 0.123 & 0.519 & 0.238 & 0.114 & 0.184 & 0.149 & 0.316 & 0.301 \\
\hline Mali & 0.036 & 0.365 & 0.036 & 0.100 & 0.464 & 0.588 & 0.012 & 0.013 & 0.936 & 0.031 & 0.008 & 0.851 \\
\hline Niger & 0.038 & 0.112 & 0.050 & 0.165 & 0.635 & 0.507 & 0.072 & 0.051 & 0.198 & 0.623 & 0.057 & 0.379 \\
\hline Nigeria & 0.110 & 0.395 & 0.166 & 0.156 & 0.173 & 0.418 & 0.006 & 0.977 & 0.009 & 0.005 & 0.004 & 1.000 \\
\hline Senegal & 0.032 & 0.082 & 0.023 & 0.777 & 0.087 & 0.494 & 0.147 & 0.058 & 0.155 & 0.578 & 0.062 & 0.480 \\
\hline Sierra Leone & 0.059 & 0.058 & 0.726 & 0.096 & 0.061 & 0.488 & 0.018 & 0.010 & 0.011 & 0.013 & 0.949 & 0.328 \\
\hline Togo & 0.051 & 0.228 & 0.060 & 0.150 & 0.510 & 0.630 & 0.073 & 0.051 & 0.144 & 0.693 & 0.040 & 0.587 \\
\hline Avg. SW & 0.274 & -0.025 & 0.502 & 0.288 & 0.614 & 0.380 & 0.207 & 1.000 & 0.866 & 0.490 & 0.315 & 0.454 \\
\hline DPC (normalized) & 0.358 & & & & & & 0.466 & & & & & \\
\hline DPC & 0.486 & & & & & & 0.573 & & & & & \\
\hline XBI & 0.924 & & & & & & 1.112 & & & & & \\
\hline
\end{tabular}


Figure 3. Characteristics of the WAMZ countries

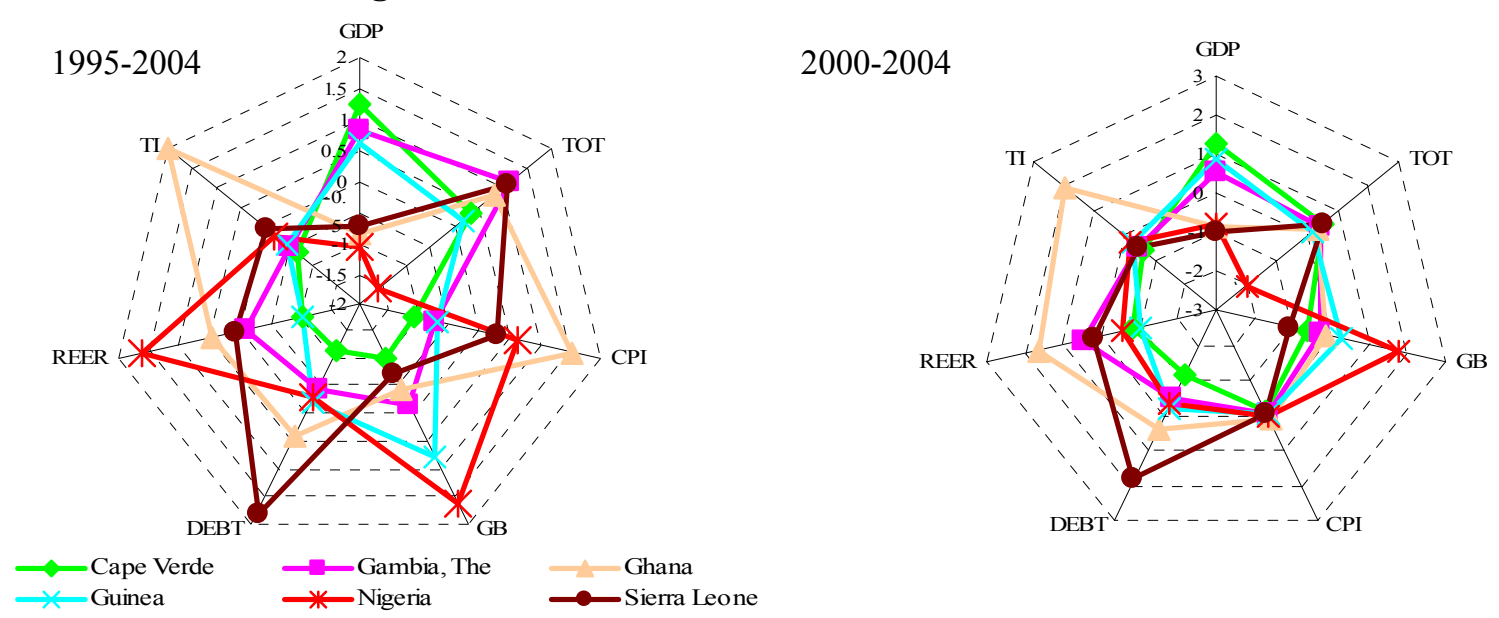

\section{Figure 4. Characteristics of the WAEMU countries}

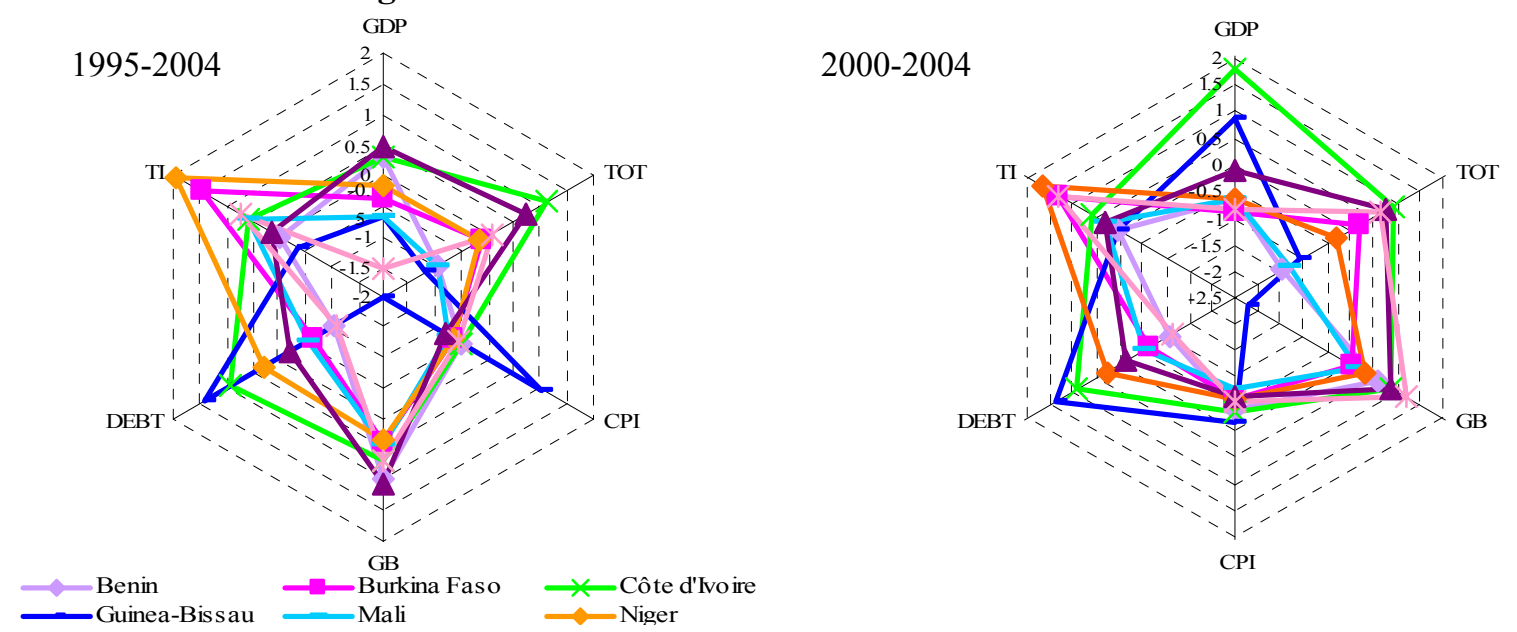

Figure 5. Characteristics of the ECOWAS countries

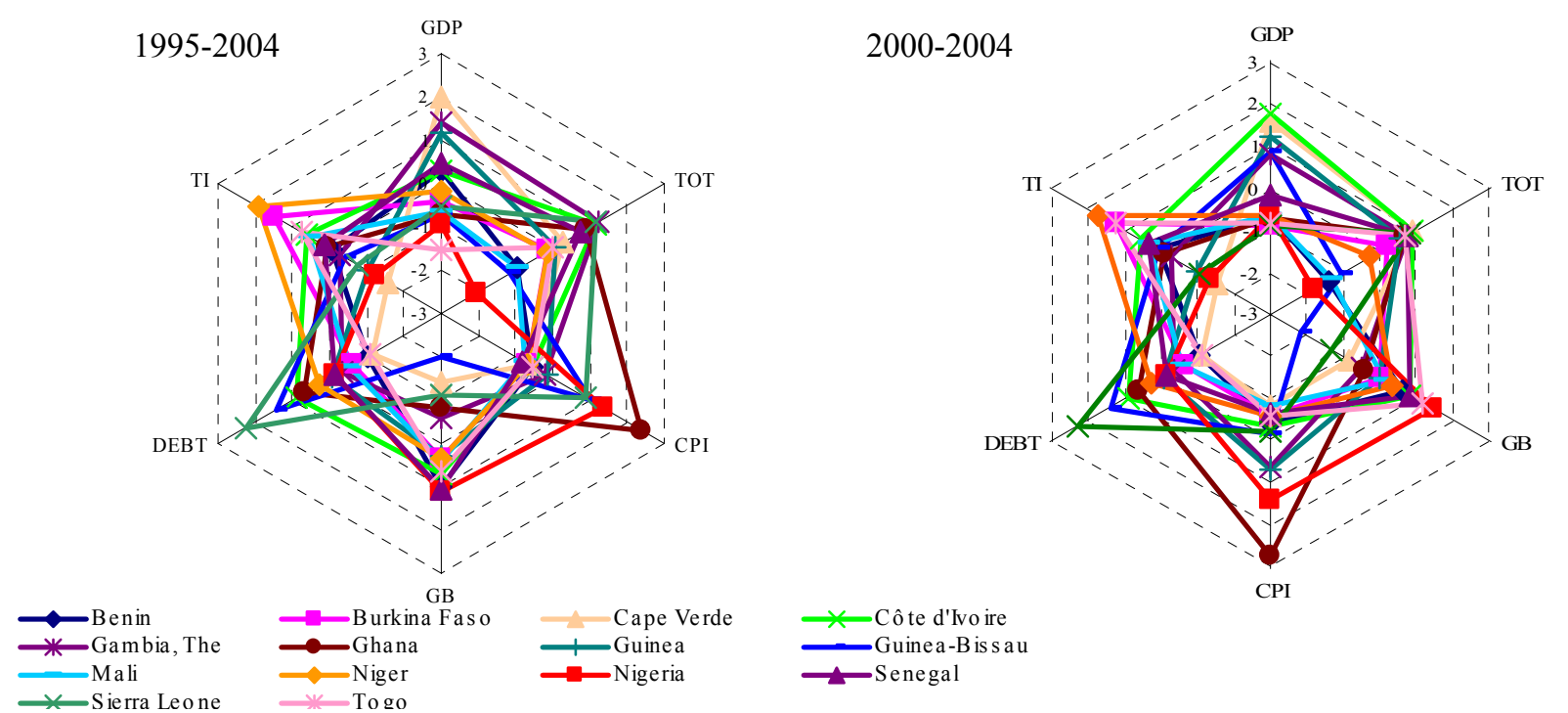

Notes: GDP is the correlation of business cycles with the euro area; TOT denotes the correlation of changes in terms of trade with the euro area; CPI is the average annual inflation rate; GB is the average government balance to GDP ratio; TI is the average trade intensity; DEBT is the average of debt servicing to exports ratio; and REER is real exchange rate variability. 
Figure 6. Clustering Based on Membership Coefficients

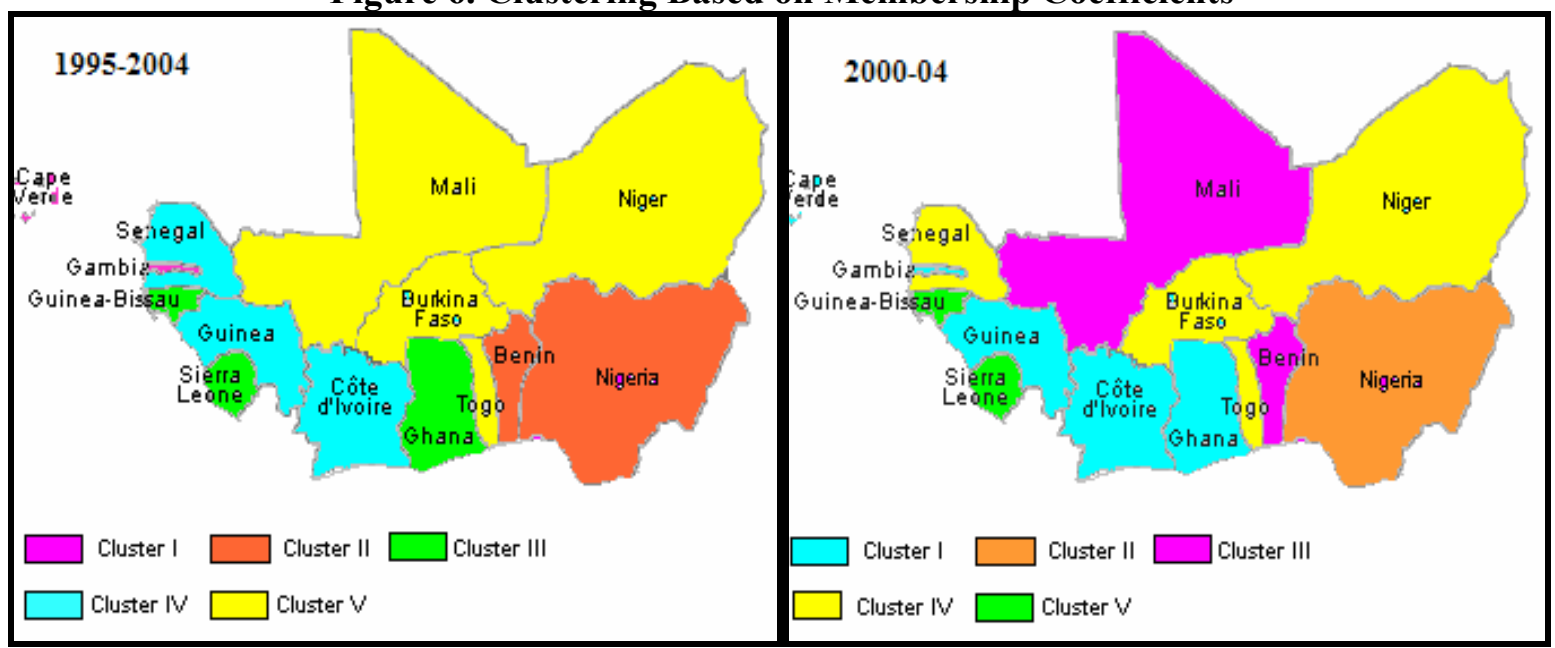

Note: Coloring of regions based on authors' calculations using fuzzy clustering, with groupings defined based on the highest membership coefficients across rows of Table 2. The maps are not for official purposes, nor do they show political boundaries.

\section{Empirical Evaluation: Principal Component Analysis}

A robustness check recommended for grouping generated from clustering analysis is the principal component analysis (PCA). PCA is a mathematical procedure for multivariate analysis, which aims to reduce the number of possibly correlated variables into a smaller number of uncorrelated variables known as the "principal components." Each principal component, $P C$, is a linear combination of the original variables and may be expressed as $P C_{i}=\alpha_{i 1} X_{1}+\alpha_{i 2} X_{2} \ldots+\alpha_{i p} X_{p} ; \quad i=1,2, \ldots, p$

where $X$ is a data matrix with $n$ observations and $p$ variables. The first principal component is supposed to account for much of the variability in data, whereas the following principal components explain the remaining percentage of variation. Often, the first few principal components explain most of the variation and the contribution of the remaining components is negligible. In a clustering context, PCA provides a way of projecting the data into a lower dimensional space, which makes visual inspection more effective as discussed in Everitt, Landau and Leese (2001). We generate principal components and examine the clustering of ECOWAS countries based on the principal components, which satisfy the following properties (i) they collectively explain at least 60 percent of the variation in data; (ii) each of the components is associated with an eigenvalue of greater than 1; and (iii) each principal component individually explains at least 20 percent of the variation.

The results show that the first two principal components satisfy the above properties for the sample of WAMZ and ECOWAS countries. ${ }^{31}$ Hence, we generate two-dimensional scatter plots of countries, measuring the first principal component on the $\mathrm{x}$-axis and the second principal component on the y-axis (Figure 7). Further, we superimpose contour maps

${ }^{31}$ The results for the PCA are presented in Appendix C. 
generated by fuzzy clustering on the scatter plots to visualize the results. ${ }^{32}$ The plot for the WAMZ countries supports the results obtained earlier. Similarly, for the ECOWAS countries, the composition of clusters is almost identical to that obtained earlier. Nigeria does not form part of any group in either case, whereas most WAEMU countries fall together. Côte d'Ivoire and Guinea-Bissau appear to be different from the rest of the WAEMU group and cluster with WAMZ countries in 2000-04.

\section{Figure 7. Clustering Based on Principal Components Analysis} (i) WAMZ Member Countries
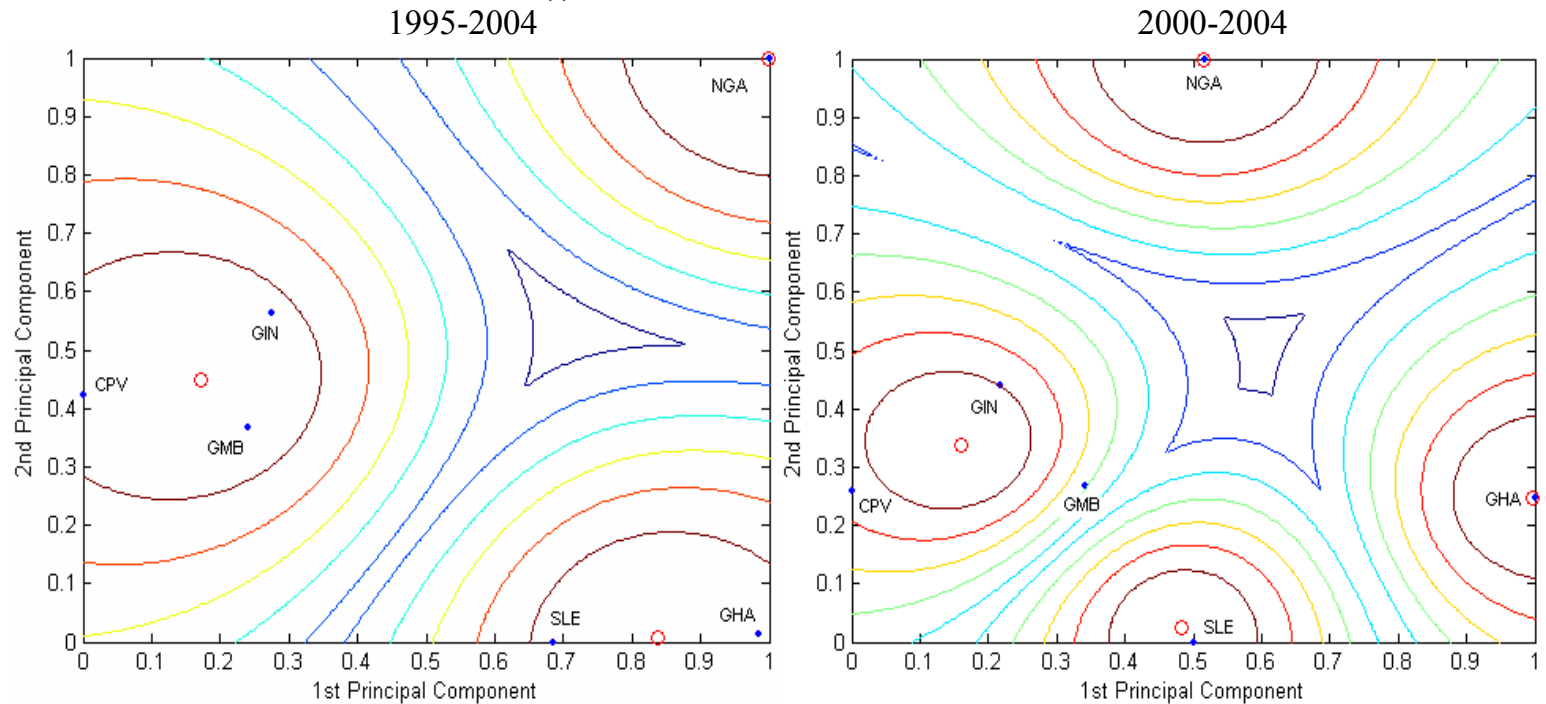

(ii) ECOWAS Member Countries

1995-2004

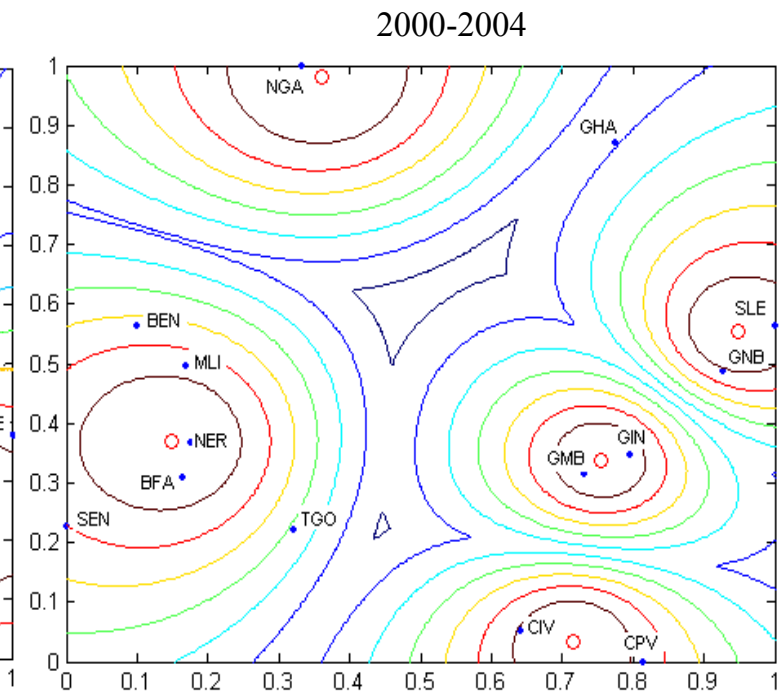

\footnotetext{
${ }^{32}$ Fuzzy clustering is performed using the first two principal components. Each big circle represents a cluster and the inner most circle within it represents the center of the cluster as obtained from the clustering results. The placement of the clusters gives an idea about the distances or similarities between them and the placement of the countries indicates the similarities within a cluster. See Balasko, Abonyi and Feil (2004) for a detailed explanation of the generation of contour maps.
} 


\section{Group Similarities: West Africa, Central Africa, and the Euro Area}

We now extend our analysis to include the central African countries and the euro area. We do this because first, given the increased interest in emulating the European experience, we would like to quantify how the euro area clustering compares with the clustering of West Africa. Second, given the geographical proximity of the West and central African regions, and the existing monetary arrangements in place in the CFA zone, it is interesting to examine similarities among countries in a larger setting and explore the feasibility of alternative monetary groupings in sub-Saharan Africa using the clustering tools.

We begin by analyzing the dissimilarity matrices of the proposed currency unions in West Africa. We calculate the average distance between a pair of objects in every group using the Euclidean distance as the dissimilarity measure, ${ }^{33}$ and compare with the average dissimilarity between countries in the Euro Area and the Central African Economic and Monetary Community (CEMAC) region. ${ }^{34}$ Table 3 shows that the WAMZ countries have the highest pair-wise average distance among themselves whereas the WAEMU countries have the highest variation in distances. However, countries in the euro area have the lowest average distance, and the CEMAC region has the lowest dispersion around the mean. ${ }^{35}$

Table 3. Dissimilarities Between Member Countries

\begin{tabular}{lcccccc}
\hline \hline & \multicolumn{2}{c}{$1990-2004$} & \multicolumn{2}{c}{ 1995-2004 } & \multicolumn{2}{c}{ 2000-04 } \\
\cline { 2 - 7 } & Mean & Std. deviation & Mean & Std. deviation & Mean & Std. deviation \\
\hline WAMZ & 3.57 & 1.15 & 3.59 & 1.21 & 3.59 & 1.09 \\
WAEMU & 3.14 & 1.50 & 3.23 & 1.09 & 3.28 & 1.14 \\
ECOWAS & 3.26 & 1.17 & 3.31 & 1.03 & 3.33 & 0.96 \\
CEMAC & 3.43 & 0.46 & 3.43 & 0.52 & 3.40 & 0.70 \\
Euro area & 2.54 & 1.24 & 2.58 & 1.09 & 2.63 & 1.03 \\
\hline \hline Source: Authors' calculations. & & & &
\end{tabular}

Figures 8, 9, and 10 present the box plots of the dissimilarity matrices for the WAMZ, WAEMU, and ECOWAS countries, respectively. The box plots summarize information on the pairwise distances between countries and facilitate comparison across countries. Each box has a line at the first quartile, the median, and the third quartile. Thus, the height of each box represents the inter-quartile range, and the lines extending from the boxes present the range of pairwise distances. ${ }^{36}$ Figure 8 indicates that the median values differ considerably across the WAMZ countries. Ghana, Nigeria, and Sierra Leone have less dispersion in their distance values but are farther away from other countries. Among WAEMU countries,

${ }^{33}$ A dissimilarity matrix presents the distance between every pair of objects in the data set. For a data set with $n$ observations, the total number of pairs of distances would be $n(n-1) / 2$.

${ }^{34}$ The euro area consists of Austria, Belgium, Finland, France, Germany, Greece, Ireland, Italy, Luxembourg, Netherlands, Portugal and Spain. Luxembourg is excluded because data on its terms of trade are unavailable. However, the euro area calculations do not include the debt-servicing variable.

${ }^{35}$ For comparison purposes, we use the same criteria for calculating distances within the euro area and CEMAC, as described in Section IV. The average distance within the euro area might decrease if the full Maastricht criteria are taken into account.

${ }^{36}$ Outliers in the data are indicated by a "+" sign. 
Guinea-Bissau has the highest median distance as well as the highest minimum and maximum distance from other countries. The median distance is lower for Burkina Faso, Mali, Niger, Senegal and Togo. When the WAEMU and the WAMZ are included in the same sample, we notice that the distance range increases for almost all countries, although the WAEMU countries continue to have lower median values.

Figure 8. Box Plot of the Distances: WAMZ Countries

1995-2004

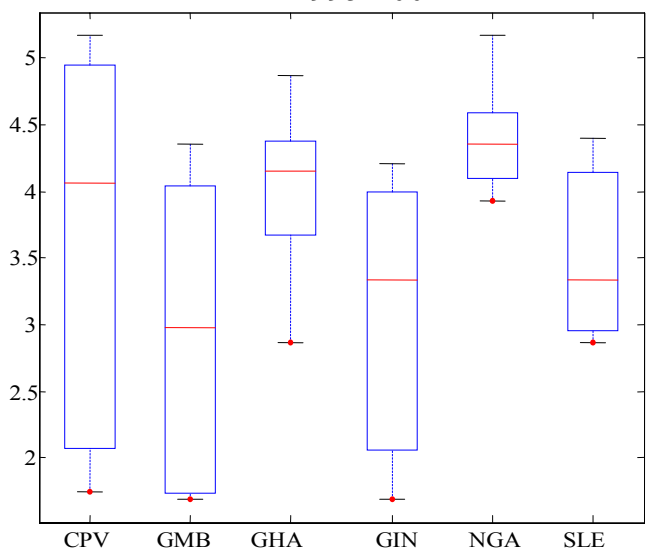

2000-2004

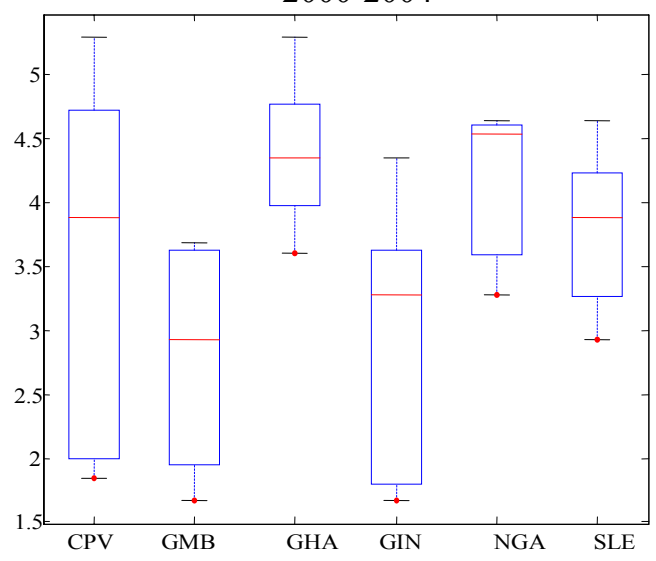

Figure 9. Box Plot of the Distances: WAEMU Countries

$1995-2004$

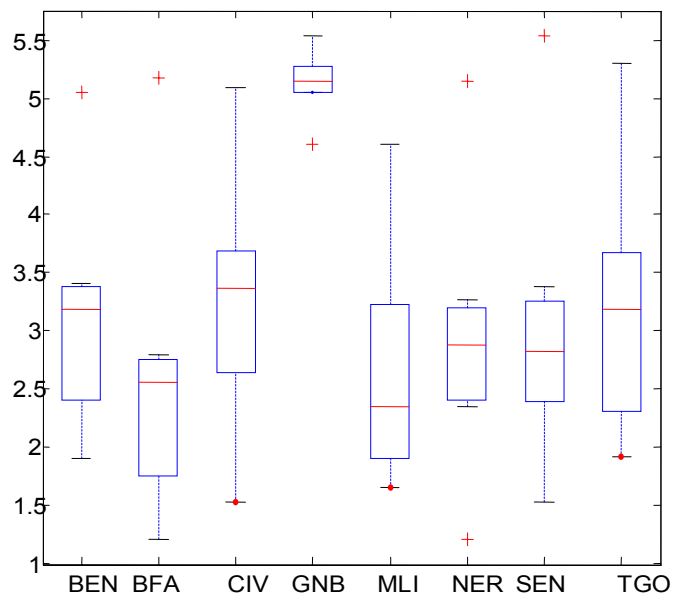

Figure 10. Box Plot of the Distances: ECOWAS Countries 1995-2004

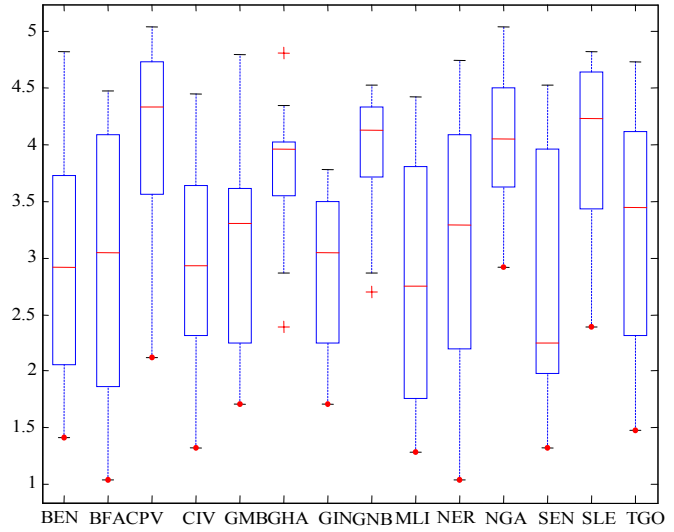

2000-2004

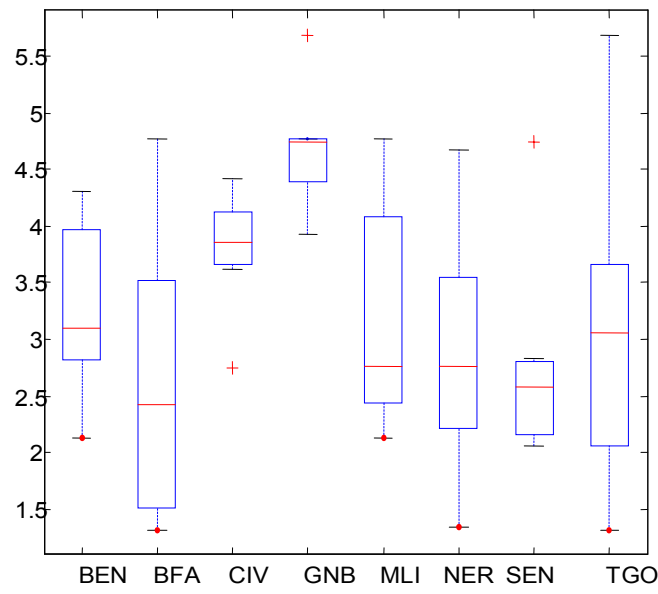

2000-2004

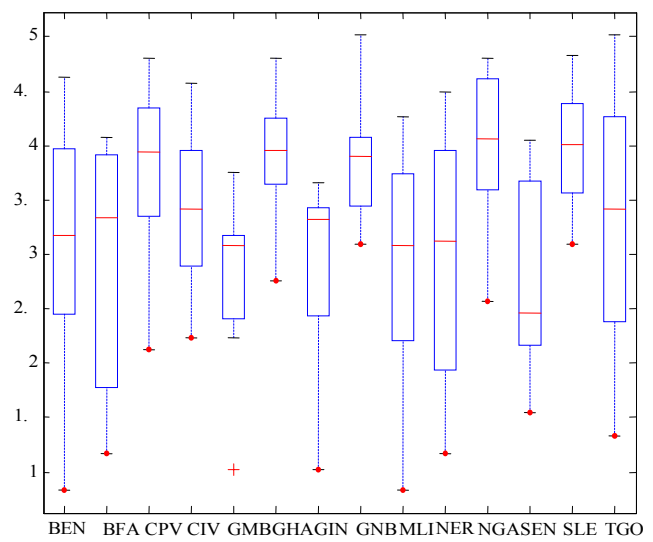


Next, we perform clustering for two different data sets. The first consists of all the countries in the WAMZ, the WAEMU and the CEMAC, and the second, the euro area. For both sets, we consider data for 1995-2004. Visual inspection of the dendrogram and the CHI obtained from the first sample suggest the presence of six clusters (Figure 11). Burkina Faso, Côte d'Ivoire, Niger, and Senegal form one group; Benin, Chad, Mali, and Togo form the second group; Cameroon and Congo group together in one cluster; Cape Verde, the Central African Republic, The Gambia, and Guinea form the fourth group; Equatorial Guinea, Gabon, and Nigeria make up the fifth group; and Ghana, Guinea-Bissau, and Sierra Leone make up the final group. The fuzzy clustering analysis supports these findings, and the optimal number of clusters, as well as the composition of clusters according to the highest membership coefficients is identical to that obtained from hierarchical clustering (Table 4). Two interesting observations emerge. First, the CEMAC and WAEMU countries, despite being members of the CFA franc zone, do not group together. The WAEMU countries form their own clusters and seem to share greater similarities, as identified by the distances at which fusions are made. Second, a majority of the WAMZ countries group with the CEMAC countries. Nigeria has relatively higher membership coefficients for clusters consisting of the CEMAC countries, which indicates that greater similarities exist among them. This is not surprising considering the heavy reliance of Nigeria and the CEMAC countries on oil for revenue. These findings are very similar to those of Bénassy-Quéré and Coupet (2005) despite differences in the time-periods and criteria used for clustering.

To examine how countries are grouped within the Euro Area, we use the same criteria as before but exclude debt-servicing. ${ }^{37}$ The cluster tree obtained from the hierarchical analysis clearly indicates the presence of two groups (Figure 12). The first group consists of Austria, Belgium, France, Germany, Italy, Portugal, and Spain, and the second group comprises of Finland, Greece, Ireland and the Netherlands. ${ }^{38}$ The validity statistics for fuzzy clustering also indicate the presence of two groups (Table 5). ${ }^{39}$ Following earlier literature on the EMU, this result can be interpreted as reflecting a "core" (Austria, Belgium, France, Germany, Italy, Portugal, and Spain) and a "periphery" (Finland, Greece, Ireland and the Netherlands) in the EMU, where the core consists of countries that are more homogeneous than the countries in the periphery (Bayoumi and Eichengreen 1993, Artis and Zhang 2001, 2002). ${ }^{40}$ Thus, in contrast to the results obtained for the WAMZ and the ECOWAS, the euro area results show a much smaller optimal number of clusters (two versus five) and greater similarities among the countries.

\footnotetext{
${ }^{37}$ Symmetry of business cycles and terms of trade changes is measured by calculating the correlation with the average of the Euro Area and trade intensity is measured as trade within the Euro Area.

${ }^{38}$ As this analysis is done for a comparison only, we do not explore the reasons for these groupings.

${ }^{39}$ Examining a larger group of European countries based on the OCA and Maastricht Criteria, Artis and Zhang $(2001,2002)$ also report the optimal number of clusters for the EU to be two or three.

${ }^{40}$ However, if the sample is split into two periods, pre-EU (1990-2001 or 1995-2001) and post-EU (2002-2004), then we obtain the interesting result that Netherlands is part of the first group in the post-EU period. This shows that after the adoption of the Euro, Netherlands became more similar to group one countries.
} 
Figure 11. Hierarchical Clustering Analysis: West and Central Africa

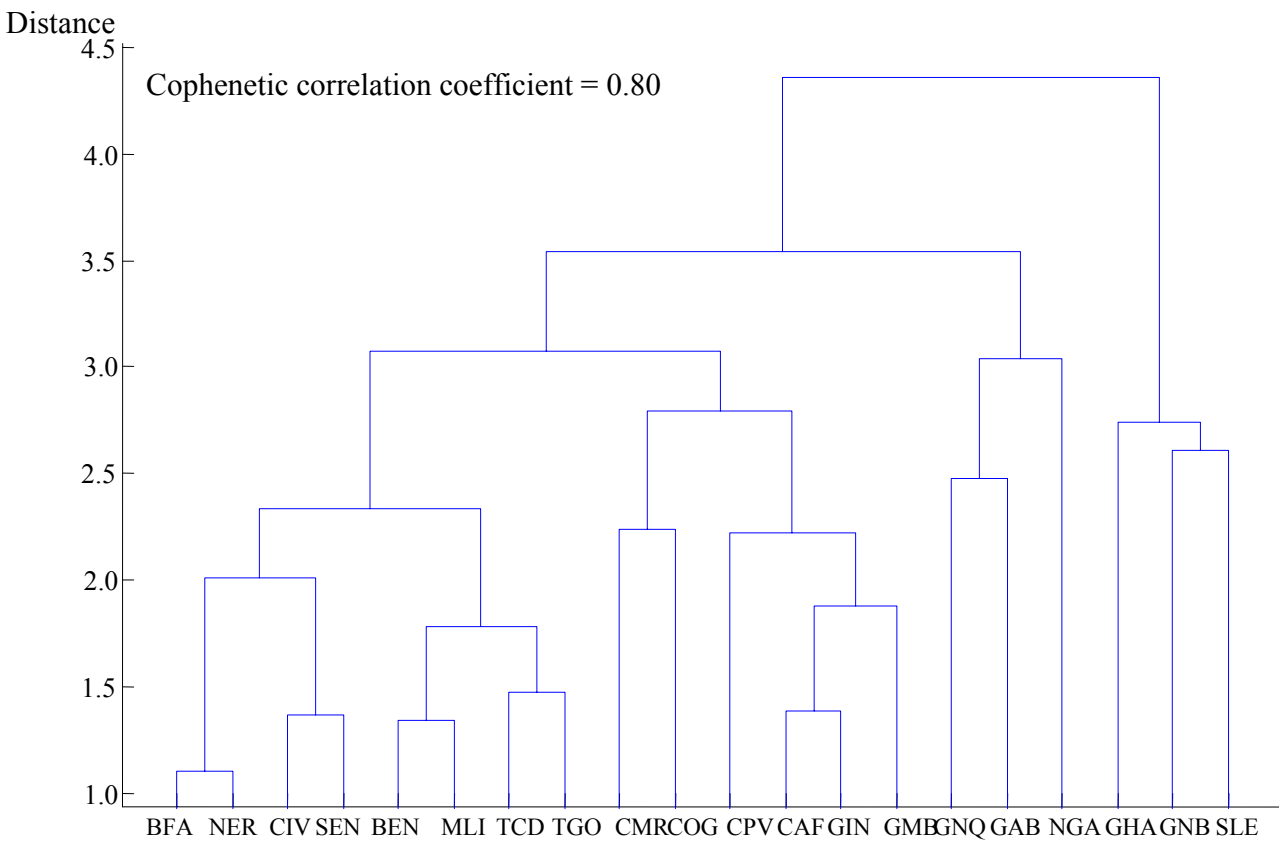

Figure 12. Hierarchical Clustering Analysis: the Euro Area

Distance

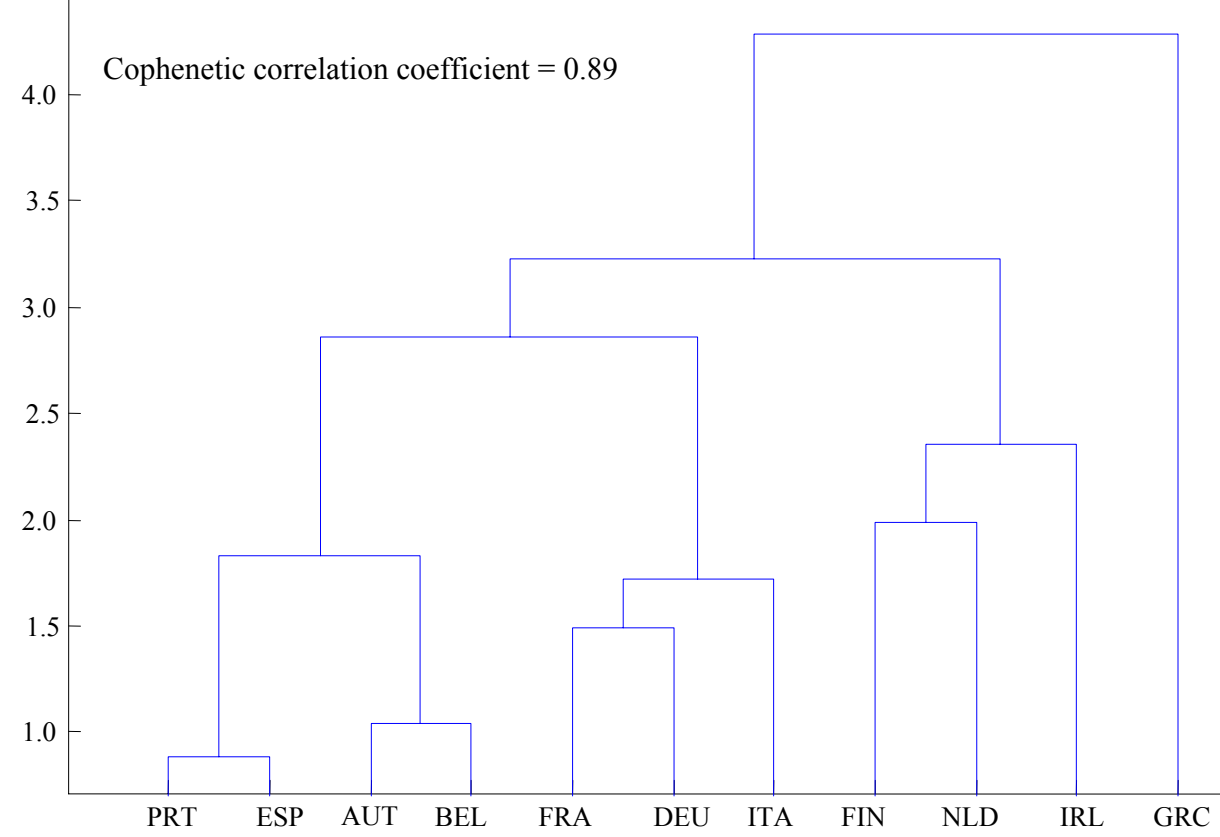

Note: See Appendix B for the list of abbreviations and the corresponding country names. 
Table 4. Fuzzy Clustering for West and Central Africa

\begin{tabular}{|c|c|c|c|c|c|c|c|}
\hline & \multicolumn{7}{|c|}{$1995-2004$} \\
\hline & I & II & III & IV & V & VI & SW \\
\hline Benin & 0.161 & 0.200 & 0.146 & 0.137 & 0.327 & 0.029 & 0.176 \\
\hline Burkina Faso & 0.032 & 0.028 & 0.040 & 0.725 & 0.159 & 0.017 & -0.081 \\
\hline Cameroon & 0.257 & 0.248 & 0.158 & 0.122 & 0.158 & 0.057 & 0.382 \\
\hline Cape Verde & 0.245 & 0.089 & 0.375 & 0.095 & 0.120 & 0.077 & 0.562 \\
\hline Central African Rep. & 0.187 & 0.118 & 0.465 & 0.086 & 0.106 & 0.038 & 0.273 \\
\hline Chad & 0.142 & 0.068 & 0.090 & 0.115 & 0.547 & 0.038 & 0.622 \\
\hline Congo, Republic of & 0.883 & 0.023 & 0.038 & 0.015 & 0.031 & 0.011 & 0.195 \\
\hline Côte d'Ivoire & 0.097 & 0.070 & 0.196 & 0.368 & 0.157 & 0.112 & 0.601 \\
\hline Equatorial Guinea & 0.035 & 0.871 & 0.026 & 0.022 & 0.036 & 0.010 & 0.097 \\
\hline Gabon & 0.187 & 0.289 & 0.127 & 0.111 & 0.221 & 0.066 & -0.112 \\
\hline Gambia, The & 0.114 & 0.053 & 0.547 & 0.113 & 0.101 & 0.074 & 0.462 \\
\hline Ghana & 0.098 & 0.070 & 0.113 & 0.109 & 0.106 & 0.505 & 0.563 \\
\hline Guinea & 0.040 & 0.014 & 0.898 & 0.018 & 0.021 & 0.010 & 0.340 \\
\hline Guinea-Bissau & 0.159 & 0.072 & 0.118 & 0.110 & 0.119 & 0.422 & 0.398 \\
\hline Mali & 0.061 & 0.047 & 0.044 & 0.145 & 0.686 & 0.017 & 0.523 \\
\hline Niger & 0.038 & 0.032 & 0.050 & 0.749 & 0.101 & 0.030 & 0.505 \\
\hline Nigeria & 0.221 & 0.278 & 0.121 & 0.100 & 0.164 & 0.113 & -0.130 \\
\hline Senegal & 0.097 & 0.077 & 0.244 & $\mathbf{0 . 3 3 2}$ & 0.203 & 0.048 & 0.376 \\
\hline Sierra Leone & 0.043 & 0.024 & 0.049 & 0.041 & 0.038 & 0.805 & 0.597 \\
\hline Togo & 0.076 & 0.078 & 0.069 & 0.229 & 0.509 & 0.039 & 0.447 \\
\hline Avg. SW & 0.289 & -0.145 & 0.410 & 0.350 & 0.424 & 0.519 & 0.340 \\
\hline DPC (normalized) & 0.280 & & & & & & \\
\hline $\mathrm{DPC}$ & 0.400 & & & & & & \\
\hline XBI & 0.871 & & & & & & \\
\hline
\end{tabular}

Notes: SW, DPC and XBI denote the silhouette width, Dunn's Partition Coefficient and Xie and Beni's Index, respectively. Avg. SW represents the average silhouette width of clusters if objects are forced to belong to each cluster according to their membership coefficients.

Table 5. Membership coefficients for the Euro Area

\begin{tabular}{lccc}
\hline \hline & & $1995-2004$ & \\
\hline \hline Austria & I & II & SW \\
Belgium & $\mathbf{0 . 6 3 1}$ & 0.369 & 0.512 \\
Finland & $\mathbf{0 . 7 2 4}$ & 0.276 & 0.622 \\
France & 0.262 & $\mathbf{0 . 7 3 8}$ & 0.278 \\
Germany & $\mathbf{0 . 7 7 5}$ & 0.225 & 0.607 \\
Greece & $\mathbf{0 . 7 7 2}$ & 0.228 & 0.569 \\
Ireland & 0.359 & $\mathbf{0 . 6 4 1}$ & 0.257 \\
Italy & 0.275 & $\mathbf{0 . 7 2 5}$ & 0.172 \\
Netherlands & $\mathbf{0 . 7 9 2}$ & 0.208 & 0.576 \\
Portugal & 0.195 & $\mathbf{0 . 8 0 5}$ & 0.190 \\
Spain & $\mathbf{0 . 5 4 6}$ & 0.454 & 0.392 \\
\hline Avg. SW & $\mathbf{0 . 6 2 9}$ & 0.371 & 0.479 \\
DPC & 0.540 & 0.224 & 0.423 \\
XBI & 0.599 & & \\
\hline \hline
\end{tabular}

Notes: SW, DPC and XBI denote the silhouette width, Dunn's Partition Coefficient and Xie and Beni's Index, respectively. Avg. SW represents the average silhouette width of clusters if objects are forced to belong to each cluster according to their membership coefficients. 


\section{Conclusion And Policy Implications}

Using hard and soft clustering and other pattern recognition analysis of countries in West Africa, this paper examines the status of the candidate countries for the proposed ECOWAS monetary union in terms of the convergence and OCA criteria. It provides insights into the similarities of countries' economic structures and identifies the existing homogeneous subgroups within the region. In addition, by studying the West and central African regions together, this analysis helps in evaluating the feasibility of new monetary arrangements and the desirability of changing the existing ones to alternative configurations in West and central Africa.

Our findings reveal considerable dissimilarities in the economic characteristics of the countries in West Africa (that is, the WAEMU and WAMZ countries viewed as one group), suggesting that the formation of ECOWAS may not be advisable at this stage. Of all the groups examined, the WAMZ countries exhibit the highest degree of dissimilarity and have little in common with the WAEMU countries, which, in principle, tend to cluster together. Furthermore, although Ghana and, especially, Nigeria usually appear as singletons and are independent of any other cluster, the remaining WAMZ countries tend to group together. This outcome casts doubt about the inclusion of Nigeria and Ghana in the proposed zone, and the feasibility of a separate monetary union that includes all the WAMZ countries and raises the question of whether a more limited monetary arrangement within WAMZ would be more feasible. Finally, when West and central Africa are examined as one group, we find heterogeneities within the CFA franc zone and some interesting similarities between the CEMAC and the WAMZ: the WAEMU and CEMAC countries do not cluster together, and the WAMZ countries tend to group with the CEMAC countries.

Identifying, on the one hand, groups of countries that have achieved a high degree of macroeconomic convergence is only the first step and may raise more questions than it answers. On the other hand, the existence of differences or heterogeneities across countries does not necessarily imply that benefits cannot be achieved through monetary integration. Thus, while interpreting our results in terms of costs and benefits, one must consider that countries that do not form part of any group might still benefit from joining the union. For example, it is worth recognizing that (as noted by Frankel and Rose, 1998, and Boreiko, 2003), if the criteria are endogenous, countries that are already members of a currency zone will have some competitive advantage over other candidate countries, and the structural changes and the harmonization process will be less difficult for them. Nonetheless, the analysis in this paper raises questions about the geographical boundaries of the existing and proposed unions, and highlights the need of undertaking further analysis to assess the merits and de-merits of the proposed unions as well as of the possible alternatives. Viewed in this light, the conclusions of our analysis could be a valuable contribution to the scholarly and policy debate over whether creation of a monetary union should precede or follow other forms of integration. 


\section{Fuzzy Clustering Validity Measures}

\section{Dunn's Partition Coefficient}

The Dunn's partition coefficient $(D P C)$ is a measure of the degree of fuzziness in the clustering outcome. It is defined as the sum of squares of all the membership coefficients divided by the number of objects in the data. That is,

$$
D P C=\sum_{i=1}^{N} \sum_{k=1}^{c} \frac{u_{i k}^{2}}{N}
$$

When each object has equal membership coefficients in all clusters, the clustering is entirely fuzzy and $D P C$ is equal to $1 / c$. However, when each object has a membership coefficient of 1 in one cluster and 0 in the others, fuzzy clustering is similar to hard clustering, and the $D P C$ is equal to one. Hence, higher values of DPC indicate less fuzziness in the structure of data. The $D P C$ may be normalized to lie in the range of $[0,1]$. The normalized Dunn's coefficient is given by

$$
D P C=\frac{c \sum_{k=1}^{N} \sum_{i=1}^{c} \frac{u_{i k}^{2}}{N}-1}{c-1} .
$$

\section{Xie and Beni's Index}

Xie and Beni's validity function, $X B I$, quantifies the ratio of total variation within clusters and the separation of clusters. It is defined as

$$
X B I=\frac{\sum_{i=1}^{N} \sum_{k=1}^{c}\left(\mu_{i k}\right)^{2} d^{2}\left(x_{i}-v_{k}\right)}{n \min _{i, k} d^{2}\left(x_{i}-v_{k}\right)} .
$$

Unlike the DPC, the aim is to minimize the value of $X B I$, for which low values indicate less variation within clusters and greater dissimilarities between clusters.

\section{Silhouette Plot}

The silhouette plot is another useful tool for assessing how well an object, a cluster or an entire data set is classified. For a partitioning of data into $c$ clusters, the average dissimilarity of an object $x_{\mathrm{i}}$ to all other objects in the cluster $v_{\mathrm{k}}$ is defined as

$$
d\left(x_{i}, v_{j}\right)=\frac{1}{n_{v_{k i}}} \sum_{i} \in v_{k}\left|x_{i}-x_{l}\right|,
$$

where $n_{v}$ is the number of objects in the cluster $v_{\mathrm{k}}$. When $x_{\mathrm{i}}$ belongs to $v_{\mathrm{k}}, d\left(x_{\mathrm{i}}, v_{\mathrm{k}}\right)$ is the average dissimilarity of $x_{\mathrm{i}}$ with all other objects in that cluster, whereas if $x_{\mathrm{i}}$ does not belong 
to $v_{\mathrm{k}}$, then $d\left(x_{\mathrm{i}}, v_{\mathrm{k}}\right)$ indicates the average dissimilarity of $x_{\mathrm{i}}$ with the other cluster $v_{\mathrm{k}}$. The silhouette width $\mathrm{s}(i)$ of $x_{\mathrm{i}}$, is therefore defined as

$$
s(i)=\frac{b(i)-a(i)}{\max [a(i), b(i)]} ;-1 \leq s(i) \leq 1,
$$

where $a(i)$ denotes the average dissimilarity of $x_{\mathrm{i}}$ within a cluster, and $b(i)$ denotes the smallest dissimilarity between $x_{\mathrm{i}}$ and the other clusters. A value of $s(i)$ close to 1 indicates that dissimilarity within the cluster is much smaller than the dissimilarity between clusters; hence, the object is well classified. If $s(i)$ is close to 0 , then $a(i)$ and $b(i)$ are approximately equal, and it is unclear which cluster the object belongs to. However, a value of $s(i)$ close to -1 indicates that dissimilarity within the cluster is greater than the smallest dissimilarity with other clusters and, hence, the object is misclassified.

The silhouette width of a cluster may be obtained by averaging the silhouette widths of the objects within a cluster. This is an indicator of how well a cluster is classified. Similarly, by averaging the silhouette widths of all clusters, the silhouette width of a data set may be calculated and is an indicator of how well the data have been partitioned. 
Table B1. Countries and Regions

\begin{tabular}{|c|c|c|c|c|c|}
\hline Country & Abbreviation & Region & Country & Abbreviation & Region \\
\hline Austria & AUT & Euro Area & Ghana & GHA & WAMZ \\
\hline Belgium & BEL & Euro Area & Greece & GRC & Euro Area \\
\hline Benin & BEN & WAEMU & Guinea & GIN & WAMZ \\
\hline Burkina Faso & BFA & WAEMU & Guinea-Bissau & GNB & WAEMU \\
\hline Cameroon & CMR & CEMAC & Ireland & IRL & Euro Area \\
\hline Cape Verde & $\mathrm{CPV}$ & WAMZ & Italy & ITA & Euro Area \\
\hline Central African Rep. & CFA & CEMAC & Mali & MLI & WAEMU \\
\hline Chad & TCD & CEMAC & Niger & NER & WAEMU \\
\hline Congo & $\mathrm{COG}$ & CEMAC & Nigeria & NGA & WAMZ \\
\hline Côte d'Ivoire & CIV & WAEMU & Netherlands & NLD & Euro Area \\
\hline Equatorial Guinea & GNQ & CEMAC & Portugal & PRT & Euro Area \\
\hline Finland & FIN & Euro Area & Senegal & SEN & WAEMU \\
\hline France & FRA & Euro Area & Sierra Leone & SLE & WAMZ \\
\hline Gabon & GAB & CEMAC & Spain & ESP & Euro Area \\
\hline Gambia, The & GMB & WAMZ & Togo & TGO & WAEMU \\
\hline Germany & DEU & Euro Area & & & \\
\hline
\end{tabular}

Table B2. Business-Cycle Correlations of ECOWAS Countries, 1995-2004

\begin{tabular}{|c|c|c|c|c|c|c|c|c|c|c|c|c|c|c|}
\hline & $\begin{array}{l}\text { BEN } \\
\end{array}$ & BFA & CPV & בCIV & GMB & $\overline{\mathrm{GHA}}$ & $\begin{array}{l}\text { GIN } \\
\end{array}$ & G GNB & 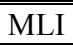 & NER & $\begin{array}{l}\text { NGA } \\
\end{array}$ & "SEN & SLE & 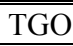 \\
\hline BEN & 1.00 & & & & & & & & & & & & & \\
\hline BFA & 0.52 & 1.00 & & & & & & & & & & & & \\
\hline CPV & 0.52 & 0.07 & 1.00 & & & & & & & & & & & \\
\hline CIV & -0.68 & -0.19 & -0.31 & 1.00 & & & & & & & & & & \\
\hline GMB & 0.12 & 0.38 & 0.58 & -0.11 & 1.00 & & & & & & & & & \\
\hline GHA & 0.45 & 0.67 & 0.02 & -0.70 & 0.32 & 1.00 & & & & & & & & \\
\hline GIN & -0.03 & 0.03 & 0.33 & 0.59 & 0.01 & -0.52 & 1.00 & & & & & & & \\
\hline GNB & -0.15 & -0.40 & -0.37 & -0.12 & -0.21 & -0.06 & -0.50 & 1.00 & & & & & & \\
\hline MLI & 0.45 & 0.82 & -0.02 & -0.14 & 0.08 & 0.45 & 0.19 & -0.42 & 1.00 & & & & & \\
\hline NER & 0.32 & 0.77 & 0.06 & 0.04 & 0.13 & 0.29 & 0.31 & -0.75 & 0.88 & 1.00 & & & & \\
\hline NGA & 0.46 & 0.63 & -0.14 & -0.54 & 0.25 & 0.75 & -0.69 & 0.30 & 0.35 & 0.14 & 1.00 & & & \\
\hline SEN & 0.28 & 0.64 & 0.39 & -0.38 & 0.84 & 0.73 & -0.24 & -0.14 & 0.33 & 0.24 & 0.59 & 1.00 & & \\
\hline SLE & 0.60 & 0.19 & 0.15 & -0.94 & -0.11 & 0.68 & -0.52 & -0.02 & 0.28 & 0.14 & 0.41 & 0.22 & 1.00 & \\
\hline TGO & 0.09 & 0.49 & -0.57 & 0.05 & -0.21 & 0.40 & -0.22 & 0.40 & 0.33 & 0.06 & 0.62 & 0.15 & -0.06 & 1.00 \\
\hline
\end{tabular}

Table B3. Changes in Terms of Trade Correlations of ECOWAS Countries, 1995-2004

\begin{tabular}{|c|c|c|c|c|c|c|c|c|c|c|c|c|c|c|}
\hline & BEN & BFA & CPV & $\overline{\text { CIV }}$ & GMB & GHA & "GIN & GNB & MLI & NER & NGA & "SEN & "SLE & TGO \\
\hline BEN & 1.00 & & & & & & & & & & & & & \\
\hline BFA & 0.46 & 1.00 & & & & & & & & & & & & \\
\hline CPV & 0.43 & 0.81 & 1.00 & & & & & & & & & & & \\
\hline CIV & 0.35 & 0.47 & 0.55 & 1.00 & & & & & & & & & & \\
\hline GMB & -0.11 & 0.14 & 0.43 & 0.76 & 1.00 & & & & & & & & & \\
\hline GHA & 0.09 & -0.15 & 0.08 & 0.54 & 0.56 & 1.00 & & & & & & & & \\
\hline GIN & -0.12 & -0.15 & 0.25 & 0.01 & 0.25 & 0.49 & 1.00 & & & & & & & \\
\hline GNB & -0.27 & -0.32 & -0.41 & -0.31 & -0.15 & -0.27 & -0.46 & 1.00 & & & & & & \\
\hline MLI & 0.94 & 0.33 & 0.36 & 0.26 & -0.09 & 0.10 & -0.05 & -0.41 & 1.00 & & & & & \\
\hline NER & -0.45 & 0.13 & 0.29 & -0.10 & 0.20 & -0.19 & 0.48 & -0.36 & -0.30 & 1.00 & & & & \\
\hline NGA & -0.13 & -0.28 & -0.57 & -0.71 & -0.77 & -0.76 & -0.51 & 0.60 & -0.20 & -0.23 & 1.00 & & & \\
\hline SEN & 0.10 & 0.09 & 0.40 & 0.42 & 0.73 & 0.47 & 0.37 & -0.52 & 0.28 & 0.24 & -0.79 & 1.00 & & \\
\hline SLE & 0.20 & 0.28 & 0.61 & 0.74 & 0.78 & 0.70 & 0.50 & -0.64 & 0.28 & 0.26 & -0.98 & 0.80 & 1.00 & \\
\hline TGO & 0.76 & 0.54 & 0.38 & 0.68 & 0.10 & 0.22 & -0.42 & -0.21 & 0.64 & -0.56 & -0.25 & 0.02 & 0.29 & 1.00 \\
\hline
\end{tabular}

Note: Terms of trade refers to the terms of trade index for goods and services. 
Figure B1. Macroeconomic Variables ECOWAS Countries, 1995-2004
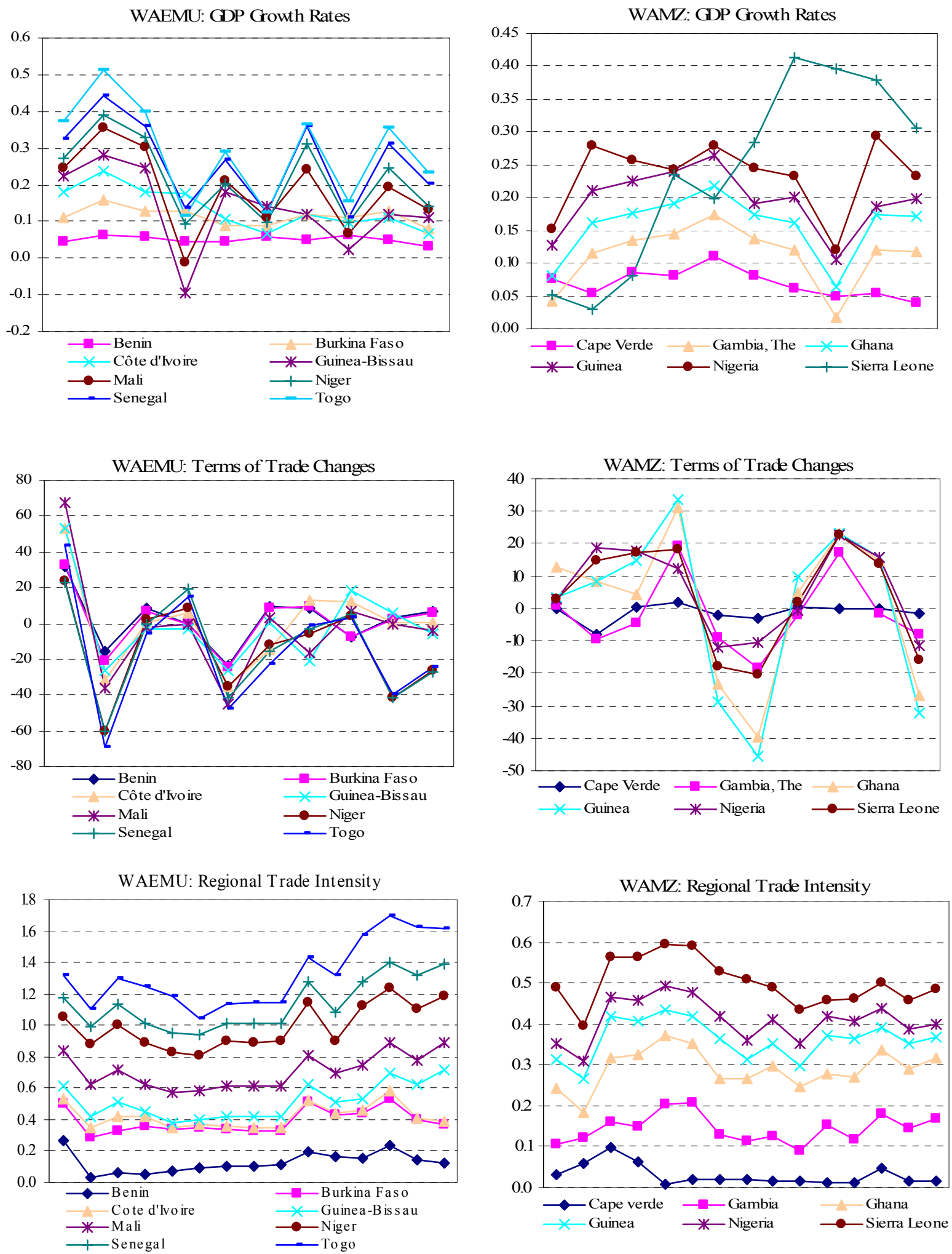
WAEMU: Annual Inflation Rate

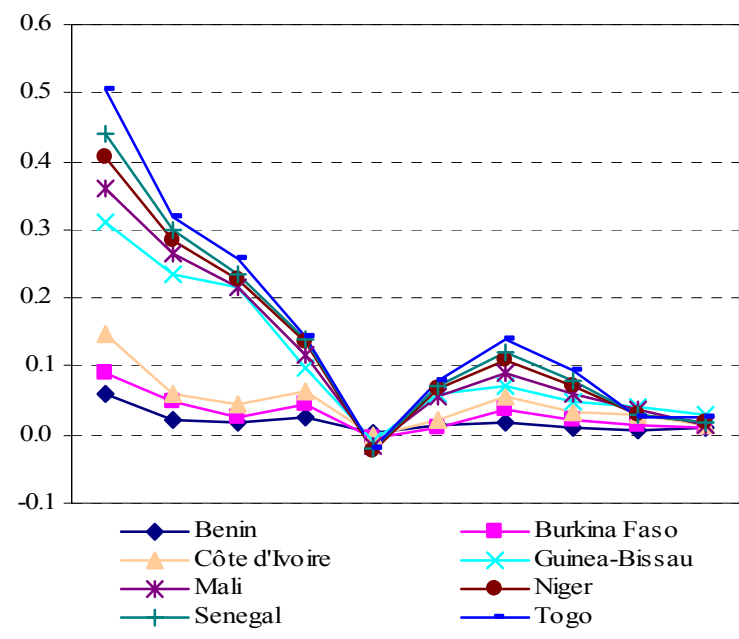

WAEMU: Government Balance to GDP Ratio
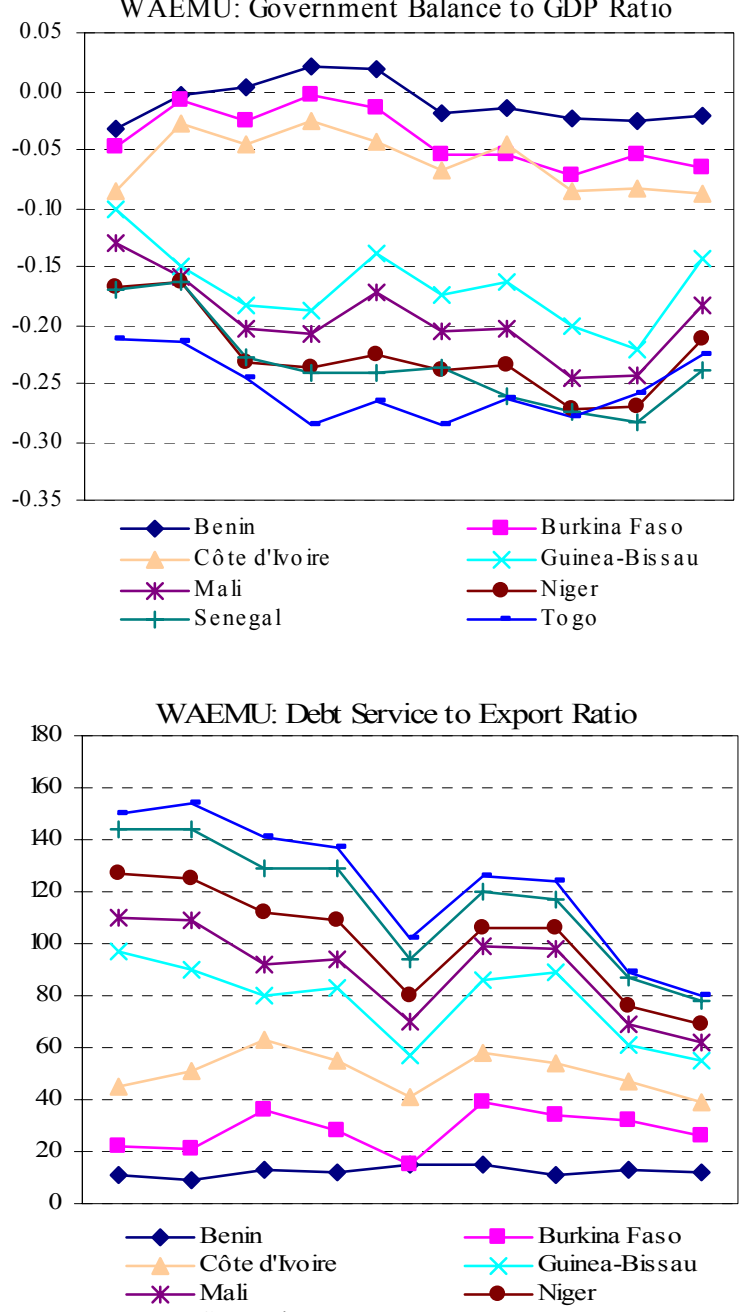

WAMZ: Annual Inflation Rate

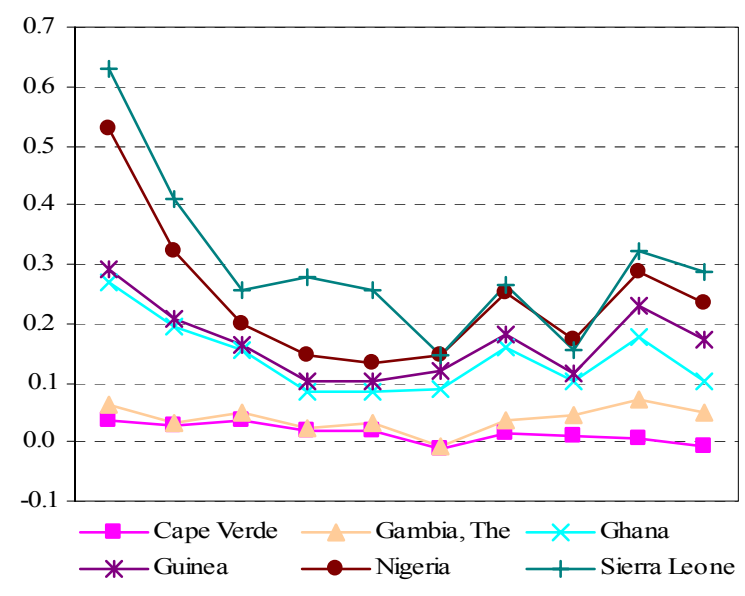

WAMZ: Government Balance to GDP Ratio
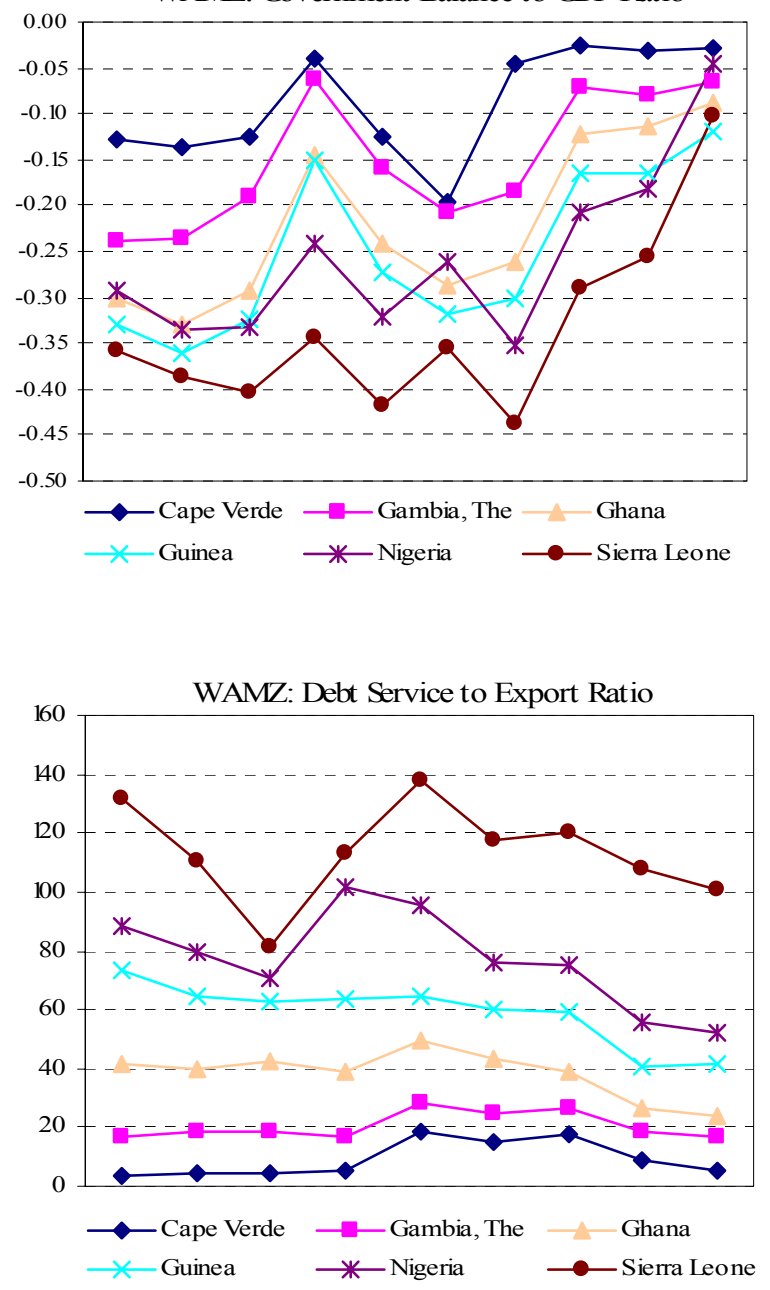


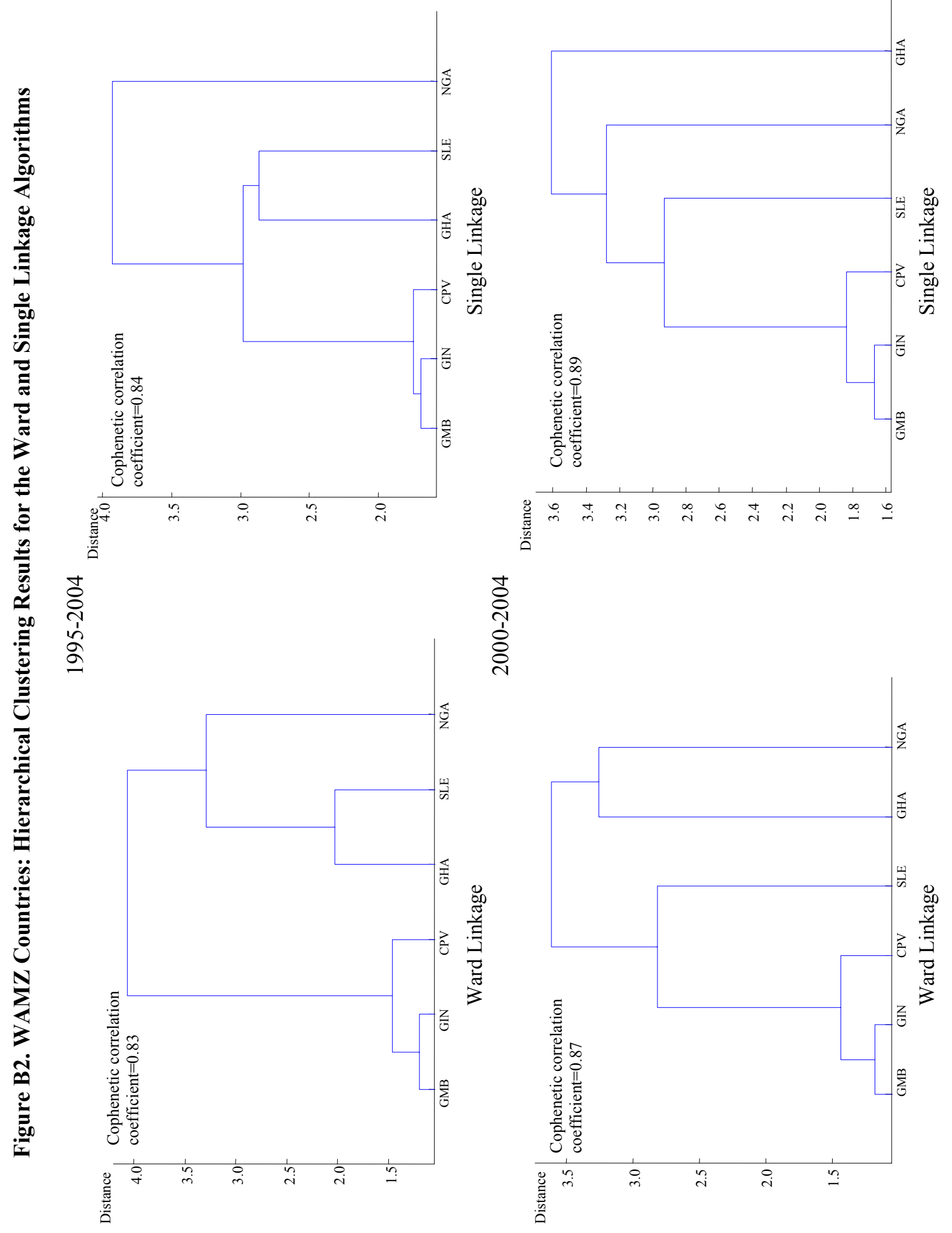




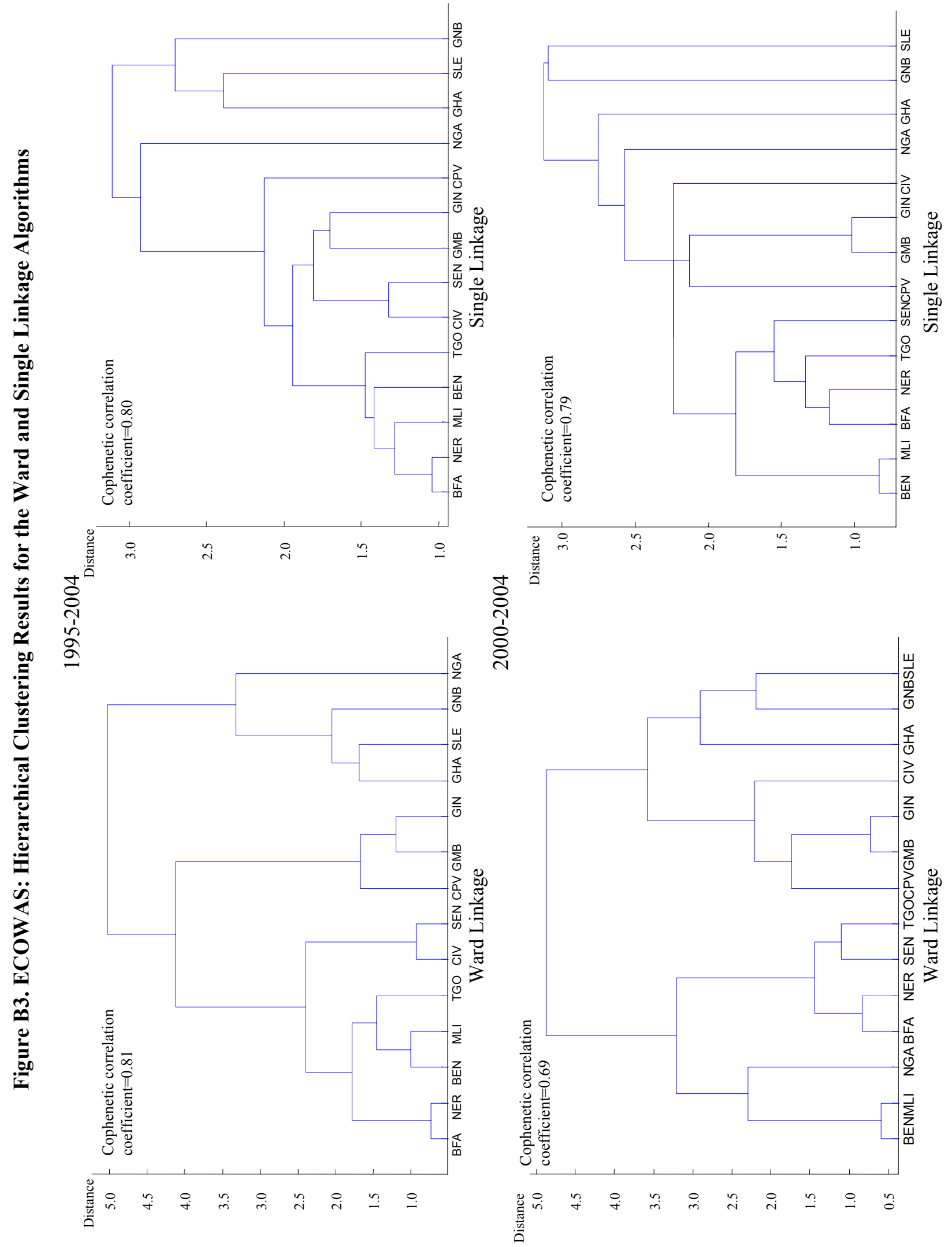


Table C1. Calinski-Harbasz Index for the Number of Clusters

\begin{tabular}{|c|c|c|c|c|c|c|c|}
\hline \multicolumn{4}{|c|}{ WAMZ } & \multicolumn{4}{|c|}{ ECOWAS } \\
\hline \multicolumn{2}{|c|}{$1995-2004$} & \multicolumn{2}{|c|}{$2000-04$} & \multicolumn{2}{|c|}{$1995-2004$} & \multicolumn{2}{|c|}{ 2000-04 } \\
\hline Clusters & F-index & Clusters & F-index & Clusters & F-index & Clusters & F-index \\
\hline 2 & 2.24 & 2 & 2.25 & 2 & 5.50 & 2 & 3.00 \\
\hline 3 & 5.35 & 3 & 3.11 & 3 & 4.78 & 3 & 3.33 \\
\hline 4 & 5.89 & 4 & 6.10 & 4 & 5.09 & 4 & 2.87 \\
\hline \multirow[t]{2}{*}{5} & 5.88 & 5 & 6.04 & 5 & 4.33 & 5 & 5.40 \\
\hline & & & & 6 & 6.45 & 6 & 5.28 \\
\hline
\end{tabular}

Table C2. Principal Component Analysis Results: WAMZ

\begin{tabular}{|c|c|c|c|c|c|c|c|c|c|c|c|c|c|c|c|}
\hline \multicolumn{8}{|c|}{ 1995-2004 } & \multicolumn{8}{|c|}{$2000-04$} \\
\hline & & \multicolumn{4}{|c|}{ Principal Components } & & \multirow{2}{*}{$\frac{\text { Variance }}{3.66}$} & \multicolumn{6}{|c|}{ Principal Components } & \multirow[b]{2}{*}{-0.08} & \multirow{2}{*}{$\begin{array}{c}\text { Variance } \\
3.19\end{array}$} \\
\hline-0.51 & 0.03 & -0.20 & -0.05 & 0.21 & -0.21 & -0.78 & & -0.46 & -0.06 & 0.49 & 0.22 & -0.34 & 0.61 & & \\
\hline-0.18 & -0.60 & 0.05 & -0.06 & 0.70 & -0.13 & 0.31 & 2.21 & -0.08 & -0.62 & 0.25 & 0.26 & -0.20 & -0.47 & 0.47 & 2.32 \\
\hline 0.50 & -0.15 & -0.24 & -0.05 & -0.10 & -0.81 & -0.08 & 0.70 & 0.07 & 0.65 & 0.01 & 0.13 & -0.28 & 0.02 & 0.71 & 1.21 \\
\hline 0.22 & 0.55 & 0.14 & -0.66 & 0.45 & -0.02 & 0.01 & 0.27 & 0.48 & 0.22 & 0.31 & 0.26 & -0.52 & -0.30 & -0.45 & 0.18 \\
\hline 0.28 & -0.39 & 0.72 & -0.19 & -0.13 & 0.10 & -0.43 & 0.16 & 0.30 & -0.29 & -0.63 & 0.42 & -0.29 & 0.40 & 0.06 & 0.09 \\
\hline 0.45 & 0.20 & 0.02 & 0.65 & 0.49 & 0.16 & -0.25 & 0 & 0.47 & -0.25 & 0.20 & -0.69 & -0.25 & 0.30 & 0.21 & 0.00 \\
\hline 0.36 & -0.34 & -0.60 & -0.32 & -0.00 & 0.50 & -0.21 & 0 & 0.48 & -0.05 & 0.40 & 0.39 & 0.61 & 0.26 & 0.11 & 0.00 \\
\hline
\end{tabular}

Notes: The results are for normalized data.

Table C3. Principal Component Analysis Results: ECOWAS

\begin{tabular}{|c|c|c|c|c|c|c|c|c|c|c|c|c|c|}
\hline \multicolumn{7}{|c|}{ 1995-2004 } & \multicolumn{7}{|c|}{$2000-04$} \\
\hline \multicolumn{6}{|c|}{ Principal Components } & Variance & \multicolumn{6}{|c|}{ Principal Components } & Variance \\
\hline-0.03 & 0.74 & -0.11 & 0.03 & -0.21 & 0.63 & 2.18 & 0.40 & -0.51 & 0.38 & -0.17 & 0.58 & -0.26 & 1.99 \\
\hline 0.15 & 0.43 & 0.66 & 0.36 & 0.41 & -0.26 & 1.65 & 0.28 & -0.51 & -0.01 & 0.72 & -0.35 & 0.15 & 1.28 \\
\hline 0.54 & -0.31 & -0.17 & 0.30 & 0.47 & 0.52 & 1.20 & -0.53 & 0.03 & 0.40 & 0.35 & 0.45 & 0.49 & 1.07 \\
\hline-0.53 & -0.21 & -0.02 & 0.80 & -0.17 & 0.12 & 0.49 & 0.25 & 0.62 & 0.29 & 0.49 & 0.11 & -0.46 & 0.87 \\
\hline 0.52 & -0.17 & 0.38 & 0.15 & -0.73 & 0.04 & 0.32 & 0.46 & 0.22 & -0.56 & 0.11 & 0.47 & 0.43 & 0.42 \\
\hline-0.35 & -0.31 & 0.62 & -0.36 & 0.09 & 0.51 & 0.16 & -0.46 & -0.22 & -0.54 & 0.27 & 0.32 & -0.52 & 0.36 \\
\hline
\end{tabular}

Note: The results are for normalized data.

Table C4. Forced Classification of ECOWAS Countries Based on Fuzzy Clustering

\begin{tabular}{|lcc|lcc|}
\hline \hline & \multicolumn{2}{|c|}{ 1995-2004 } & & \multicolumn{2}{c|}{ 2000-04 } \\
\hline \hline Country & Closest Crisp Cluster & Closest Neighbor Cluster & Country & Closest Crisp Cluster & Closest Neighbor Cluster \\
BEN & 2 & 5 & BEN & 3 & 4 \\
BFA & 5 & 2 & BFA & 4 & 3 \\
CPV & 1 & 4 & CPV & 1 & 3 \\
CIV & 4 & 5 & CIV & 1 & 4 \\
GMB & 1 & 4 & GMB & 1 & 4 \\
GHA & 3 & 4 & GHA & 1 & 5 \\
GIN & 4 & 1 & GIN & 1 & 4 \\
GNB & 3 & 2 & GNB & 5 & 4 \\
MLI & 5 & 2 & MLI & 3 & 3 \\
NER & 5 & 4 & NER & 4 & 3 \\
NGA & 2 & 5 & NGA & 2 & 3 \\
SEN & 4 & 5 & SEN & 4 & 3 \\
SLE & 3 & SLE & 5 & 3 \\
TGO & 5 & 2 & TGO & 4 & 3 \\
\hline \hline
\end{tabular}




\section{References}

Artis, M.J., and W. Zhang, 2001, “Core and Periphery in EMU: A Cluster Analysis,” Economic Issues, Vol. 6, No. 2, pp. 39-58.

, 2002, "Membership of EMU: A Fuzzy Clustering Analysis of Alternative Criteria," Journal of Economic Integration, Vol. 17, No. 1, pp. 54-79.

Balasko, B., J. Abonyi, and B. Feil, 2004, Fuzzy Clustering and Data Analysis Toolbox: For Use with Matlab, (Hungary: University of Veszprem).

Bayoumi, T., and B. Eichengreen, 1993, "Shocking Aspects of European Monetary Integration" in Adjustment and Growth in the European Monetary Union, ed. by F. Torres and F. Giavazzi (Cambridge and New York: Cambridge University Press).

, 1994, "One Money or Many? Analyzing the Prospects for Monetary Unification in Various Parts of the World," Princeton Studies in International Finance No. 76 (Princeton: Princeton University Press).

Bayoumi, T., and J.D. Ostry, 1997, "Macroeconomic Shocks and Trade Flows Within SubSaharan Africa: Implications for Optimum Currency Arrangements," Journal of African Economies, Vol. 6, No. 3, pp. 412-44.

Bénassy-Quéré, A., and M. Coupet, 2005, “On the Adequacy of Monetary Arrangements in SubSaharan Africa," World Economy, pp. 349-73.

Bezdek, J.C., 1981, Pattern Recognition with Fuzzy Objective Function Algorithms (New York: Plenum Press).

Blanchard, O., and L. Katz, 1992, "Regional Evolutions," Brookings Papers on Economic Activity: 2, pp. 1-61.

Boreiko, D., 2003, "EMU and Accession Countries: Fuzzy Cluster Analysis of Membership," International Journal of Finance and Economics, Vol. 8, pp. 309-25.

Calinski, T., and J. Harabasz, 1974, “A Dendrite Method for Cluster Analysis,” Communications in Statistics, Vol. 3, pp. 1-27.

Cashin, P., and C. Pattillo, 2000, "Terms of Trade Shocks in Africa: Are They Short-Lived or Long-Lived?” IMF Working Paper 00/72 (Washington: International Monetary Fund).

Celasun, O., and A. Justiniano, 2006, "Synchronization of Output Fluctuations in West Africa: Implications for Monetary Unification” IMF Working Paper, forthcoming.

Cohen, B.J., 1998, The Geography of Money (Ithaca, NY: Cornell University Press). 
Collier, P., 1991, “Africa's External Economic Relations, 1960-1990,” African Affairs, Vol. 90, pp. 339-56.

De Grauwe, P., and W. Vanhaverbeke, 1993, "Is Europe an Optimal Currency Area? Evidence from Regional Data," in Policy Issues in the Operation of Currency Unions, ed. by P. Masson and M. Taylor (Cambridge: Cambridge University Press).

Debrun, X., P. Masson, and C. Pattillo, 2005, "Monetary Union in West Africa: Who Might Gain, Who Might Lose, and Why?" Canadian Journal of Economics, Vol. 38, No. 2, pp. 454-81.

Devarajan, S., and D. Rodrik, 1991, "Do the Benefits of Fixed Exchange Rates Outweigh their Costs? The Franc Zone in Africa," NBER Working Paper No. 3727.

Dunn, J. C., 1974, "Well-separated clusters and the optimal fuzzy partitions," Journal of Cybernetics, Vol. 4, pp. 95-104.

Ebaldawi, I., and N. Madj, 1996, Adjustment and Economic Performance Under a Fixed Exchange Rate: A Comparative Analysis of the CFA Zone, World Development, Vol. 24, pp. 939-51.

Everitt, B.S., S. Landau, and M. Leese, 2001, Cluster Analysis (London: Arnold).

Fielding, D., and K. Shields, 2001, "Modeling Macroeconomic Shocks in the CFA Franc Zone," Journal of Development Economics, Vol. 66, pp. 199-223.

Frankel, J.A., and A.K. Rose, 1998, "The Endogeneity of the Optimum Currency Area Criteria," Economic Journal, Vol. 108, pp. 1009-25.

Ghura, D., and M.T. Hadjimichael, 1996, "Growth in Sub-Saharan Africa," IMF Staff Papers, Vol. 43, pp. 605-34.

Hadjimichael, M.T., and M. Galy, 1997, “The CFA Franc Zone and the EMU,” IMF Working Paper No. 97/156 (Washington: International Monetary Fund).

Hoffmaister, A.W., J. Roldos, and P. Wickham, 1998, "Macroeconomic Fluctuations in SubSaharan Africa,” IMF Staff Papers, Vol. 45, pp. 132-60.

Kaufman, L., and P.J. Rousseeuw, 1990, Finding Groups in Data: An Introduction to Cluster Analysis (New York: John Wiley \& Sons).

Kenen, P.B., 1969, “The Theory of Optimum Currency Areas: An Eclectic View," in Monetary Problems of the International Economy, ed. by R.A. Mundell and A.K. Swoboda (Chicago: University of Chicago Press). 
Kozluk, T., 2003, "CEEC Accession Countries and the EMU: An Assessment of Relative Suitability and Readiness for Euro-Area Membership," presented at European University Institute conference "Economic, Econometric and Cross-Disciplinary Aspects of European Union Enlargement," May 13-15 2004, Italy.

Krugman, P., 1990, "Policy Problems of a Monetary Union," in The European Monetary System in the 1990s, ed. by P. De Grauwe and L. Papademos (London and New York: Longman).

Lafrance, R., and P. St-Amant, 1999, “Optimal Currency Areas: A Review of Recent Literature,” Bank of Canada Working Paper No. 99-16 (Ontario: Bank of Canada).

Lane, P., 1996, “Stabilization Policy in a Currency Union,” Economics Letters, Vol. 53, pp. 53-60.

Masson, P., and M. Taylor, 1993, "Currency Unions: A Survey of the Issues," in Policy Issues in the Operation of Currency Unions, ed. by P. Masson and M. Taylor (Cambridge: Cambridge University Press).

Masson, P., and C. Pattillo, 2001, Monetary Union in West Africa (ECOWAS): Is it Desirable and How Could it be Achieved? IMF Occasional Paper No. 204 (Washington: International Monetary Fund). , 2005, The Monetary Geography of Africa (Washington: Brookings Institution Press).

McKinnon, R.I., 1963, “Optimum Currency Area,” American Economic Review, Vol. 53, pp. 717-24.

Milligan, G.W., and M.C. Cooper, 1985, "An Examination of Procedures for Determining the Number of Clusters in a Data Set," Psychometrika, Vol. 50, pp. 159-179.

Mundell, R.A., 1961, “A Theory of Optimum Currency Areas,” American Economic Review, Vol. 53, pp. 657-64.

Ogunkola, E.O., 2002, "The Second Monetary Zone in West Africa and the Future of a Single Monetary Zone in Sub-Saharan Africa," mimeo (National University of Lesotho).

Rouben, M., 1982, "Fuzzy Clustering Algorithms and their Clustering Validity," European Journal of Operational Research, Vol. 10, pp. 294-301.

Rousseeuw, P.J., 1987, “A Graphical Aid of Cluster Analysis,” Journal of Computer Applied Math, Vol. 20, pp. 53-65.

van den Boogaerde, P., and C. Tsangarides, 2005, "Ten Years After the CFA Franc Devaluation: Progress Toward Regional Integration in the WAEMU," IMF Working Paper No. 05/145 (Washington: International Monetary Fund). 
Xie, X. and Beni G., 1991, “A Validity Measure for Fuzzy Clustering,” IEEE Transactions on Pattern Analysis and Machine Intelligence, Vol. 13, pp. 841-47.

Zadeh, L., 1965, "Fuzzy Sets," Information and Control, Vol. 8, pp. 338-53.

Zimmerman, H.J., 1996, Fuzzy Set Theory and its Applications, $3^{\text {rd }}$ ed. (Dodrecht: Kluwer). 